\title{
Review and Progress towards the Capacity Boost of Overhead and Underground Medium-Voltage and Low-Voltage Broadband over Power Lines Networks: Cooperative Communications through Two- and Three-Hop Repeater Systems
}

\author{
Athanasios G. Lazaropoulos \\ School of Electrical and Computer Engineering, National Technical University of Athens, \\ 9 Iroon Polytechniou Street, Zografou, 15780 Athens, Greece \\ Correspondence should be addressed to Athanasios G. Lazaropoulos; aglazaropoulos@gmail.com
}

Received 30 November 2012; Accepted 8 January 2013

Academic Editors: J. Abu Qahouq and G. Maruccio

Copyright (C) 2013 Athanasios G. Lazaropoulos. This is an open access article distributed under the Creative Commons Attribution License, which permits unrestricted use, distribution, and reproduction in any medium, provided the original work is properly cited.

This paper reviews and analyzes the broadband capacity and the coexistence potential of overhead and underground mediumvoltage/broadband over power lines (MV/BPL) and low-voltage/broadband over power lines (LV/BPL) topologies when one and two repeaters are additively deployed between their existing transmitting and receiving ends (overhead and underground MV/BPL and LV/BPL topologies with two- and three-hop repeater system, respectively). The contribution of this paper is four fold. First, the factors that influence the broadband capacity performance of overhead and underground MV/BPL and LV/BPL topologies with multihop repeater systems are identified, namely the number of repeaters, the distribution power grid type-either overhead or underground, either MV or LV, the initial distribution BPL topology, the multiconductor transmission line configuration, and coupling scheme applied. Second, the well-validated applicability of two-hop repeater systems is now extended in overhead and underground LV/BPL and MV/BPL networks. The significant mitigating role of two-hop repeater systems against capacity losses due to aggravated topologies or different coupling schemes is verified. Third, the deployment upgrade of two- to three-hop repeater systems in distribution BPL topologies is first examined in terms of broadband capacity performance. To study the occurred capacity improvement, suitable capacity contour plots are first proposed. Fourth, multi-hop repeater systems are identified as valuable technology solution so that the required intraoperability between overhead and underground MV/BPL and LV/BPL networks, which is a prerequisite condition before BPL systems symbiosis with other broadband technologies (interoperability), is promoted.

\section{Introduction}

The limited investments made in the energy sector during the last decades, as well as the integration of new smart grid (SG) requirements such as the renewable and distributed energy source integration, microgrids, demand side management, and demand response programs trigger significant efforts towards modernization of power distribution grid-either overhead or underground, either medium voltage (MV) or low voltage (LV) power grids- $[1,2]$. The deployment of broadband over power lines (BPL) networks across the entire distribution grid can help towards the development of an advanced IP-based power system equipped with a plethora of SG applications [3-5].

Exploiting the strong aspects of multihop and relay-based communications, which have been studied either in wireless [6-8] or in BPL environments [9-15], the distribution BPL networks that consist of the cascade of respective distribution BPL topologies are upgraded through the ad hoc insertion of repeaters between their existing transmitting and receiving ends. These upgraded topologies are referred to as distribution BPL topologies with two- or three-hop repeater systems 
when one or two repeaters are deployed, respectively. Due to this insertion of one or two repeaters across their end-to-end transmission paths, the upgraded distribution BPL topologies consist of two or three new distribution BPL connections, respectively.

The well-established hybrid method, which is usually employed to examine the spectral behavior of various BPL channels installed on multiconductor transmission line (MTL) structures, is also adopted in this paper [1, 3, 16-23]. Based on its accurate numerical results, several factors affecting broadband capacity performance of either conventional distribution BPL topologies (i.e., distribution BPL topologies where no repeaters are installed) or upgraded distribution BPL topologies with multihop repeater system (either twoor three-hop repeater systems) are identified, namely, the number of repeaters, the allocation of the repeaters across the end-to-end transmission paths, the distribution power grid type-either overhead or underground, either MV or LV - the power grid topology, the MTL configuration, and the coupling scheme applied that is, how the BPL signal is injected onto power lines.

Already verified in the case of overhead transmission BPL networks in [13], the applicability of two-hop repeater systems is now extended in order to further harmonize distribution BPL networks. More specifically, in the case of distribution BPL topologies, two-hop repeater systems are proven to be effective remedy for the capacity losses that occur due to either aggravated BPL topologies or less spectral-efficient coupling schemes.

Expanding the concept of two-hop repeater systems, the capacity performance of distribution BPL topologies with three-hop repeater systems is first investigated. It is verified that three-hop repeater systems assure even higher capacity performance and greater capacity flexibility in comparison with two-hop ones for a great number of different power grid types and distribution BPL topologies. Actually, the significant capacity boost through the implementation of three-hop repeater systems is studied through the capacity metric of capacity contour plots.

Therefore, exploiting common and/or scalable capacity capabilities offered by the deployment of multihop repeater systems among different distribution BPL networks, new significant and interesting capacity tradeoffs may occur. In addition, the combination of scalable capacities with standardized topologies offers a decisive step towards the intraoperability of distribution BPL networks that is, coexistence and integration of distribution BPL topologies in a SG environment.

The rest of this paper is organized as follows. In Section 2, an overview of the factors, which influence capacity behavior, that concern BPL transmission via overhead and underground MV and LV power grid is given. In Section 3, the modal behavior of BPL propagation is discussed along with the necessary assumptions concerning BPL signal transmission. Section 4 deals with noise characteristics, electromagnetic interference (EMI) regulations and their respective power constraints, and the evaluation of the capacity delivered by distribution BPL networks when multihop repeater systems are deployed. Section 5 deals with simulations of various overhead and underground MV/BPL and LV/BPL topologies aiming at marking out how two-hop repeater systems may improve broadband capacity performance when different distribution BPL topologies and coupling schemes occur. In addition, the importance of installing three-hop repeater systems across conventional distribution BPL networks is highlighted through the capacity contour plots. Section 6 concludes this paper.

\section{Overview of Overhead and Underground MV/BPL and LV/BPL MTL Configurations}

2.1. The Overhead MV Power Distribution Grid. A typical case of overhead MV distribution line is depicted in Figure 1(a). Overhead MV distribution lines hang at typical heights $h_{\mathrm{MV}}$ ranging from $8 \mathrm{~m}$ to $10 \mathrm{~m}$ above ground. Typically, three parallel noninsulated phase conductors spaced by $\Delta_{\mathrm{MV}}$ in the range from $0.3 \mathrm{~m}$ to $1 \mathrm{~m}$ are used above lossy ground. This three-phase overhead MV distribution line configuration is considered in the present work consisting of ACSR $3 \times$ $95 \mathrm{~mm}^{2}$ conductors $[1,3,17,18,24,25]$.

The ground is considered as the reference conductor. The conductivity of the ground is assumed $\sigma_{g}=5 \mathrm{mS} / \mathrm{m}$ and its relative permittivity $\varepsilon_{r g}=13$, which is a realistic scenario [3, $13,17-19,21,23,25,26]$. The impact of imperfect ground on signal propagation over power lines was analyzed in $[17,18$, 21, 23, 25-27].

2.2. The Overhead LV Power Distribution Grid. A typical case of overhead LV distribution line is depicted in Figure 1(b). Four parallel noninsulated conductors are suspended one above the other spaced by $\Delta_{\mathrm{LV}}$ in the range from $0.3 \mathrm{~m}$ to $0.5 \mathrm{~m}$ and located at heights $h_{\mathrm{LV}}$ ranging from $6 \mathrm{~m}$ to $10 \mathrm{~m}$ above ground for the lowest conductor. The upper conductor is the neutral, while the lower three conductors are the three phases. This three-phase four-conductor overhead LV distribution line configuration is considered in the present work consisting of ASTER $3 \times 54.6 \mathrm{~mm}^{2}+1 \times 34.4 \mathrm{~mm}^{2}$ conductors [3, 28-31]. The ground is considered as the reference conductor as well as it is characterized by the aforementioned properties.

2.3. The Underground $M V$ Power Distribution Grid. The underground MV distribution line that will be examined is the three-phase sector-type PILC distribution-class cable $\left(8 / 10 \mathrm{kV}, 3 \times 95 \mathrm{~mm}^{2} \mathrm{Cu}\right.$, PILC) buried $1 \mathrm{~m}$ inside the ground with the aforementioned ground properties. The cable arrangement consists of the three-phase three-sectortype conductors, one shield conductor, and one armor conductor, see Figure 1(c). The shield and the armor are grounded at both ends $[3,19,28,32,33]$. The shield acts as a ground return path and as a reference conductor $[3,21$, 24, 34-36]. Signal transmission via three-phase underground power lines has been analyzed in $[19,21,34,35,37]$ where the analytical formulation has been demonstrated. 


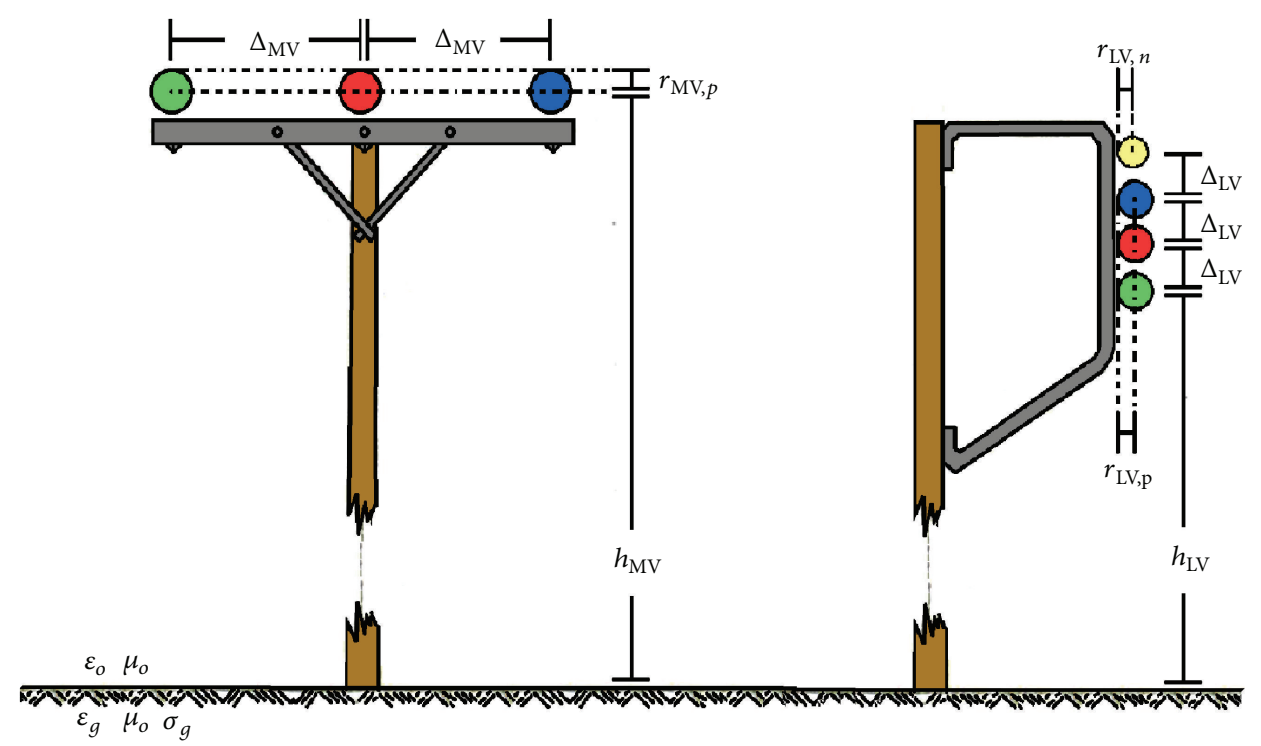

(a)

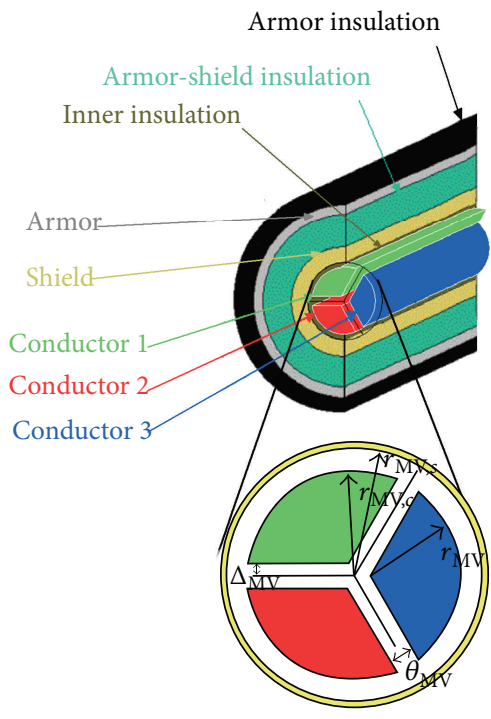

(c) (b)

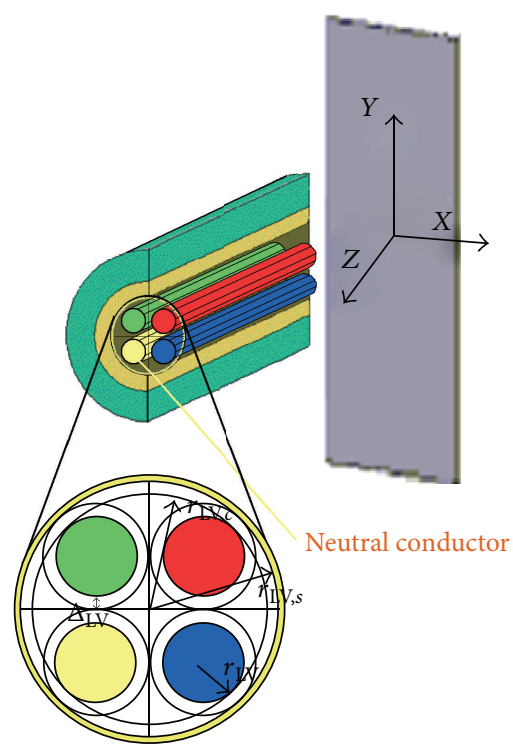

(d)

Figure 1: Typical multiconductor structures [3]. (a) Overhead MV. (b) Overhead LV. (c) Underground MV. (d) Underground LV.

2.4. The Underground LV Power Distribution Grid. The underground LV distribution line that will be examined in this paper is the three-phase four-conductor core-type YJV underground LV distribution cable $\left(4 \times 25 \mathrm{~mm}^{2} \mathrm{Cu}\right.$, XLPE) buried $1 \mathrm{~m}$ inside the ground with the aforementioned ground properties. The layout of this cable is depicted in Figure 1(d). The cable arrangement consists of the three-phase three-coretype conductors, one core-type neutral conductor, and one shield conductor. The shield is grounded at both ends and acts as a ground return path and as a reference conductor [21]. Signal transmission via three-phase underground power lines has been analyzed in $[16,19,21]$ where the analytical formulation has been demonstrated.
2.5. Indicative Overhead and Underground Distribution BPL Topologies. In accordance with $[3,13,16,24-26,28,34,38-$ 43], average path lengths of the order of $1000 \mathrm{~m}$ and $200 \mathrm{~m}$ are encountered in overhead and underground distribution BPL topologies, respectively.

With reference to Figure 2, five indicative overhead distribution BPL topologies concerning end-to-end connections of average lengths equal to $1000 \mathrm{~m}$, which are detailed in Table 1, are examined, namely, (i) overhead urban case A, (ii) overhead urban case B, (iii) overhead suburban case (iv) overhead rural case and ( $\mathrm{v}$ ) overhead "LOS" transmission along the same end-to-end distance $L=L_{1}+\cdots+L_{N+1}=1000 \mathrm{~m}$. This topology corresponds to Line of Sight transmission in 


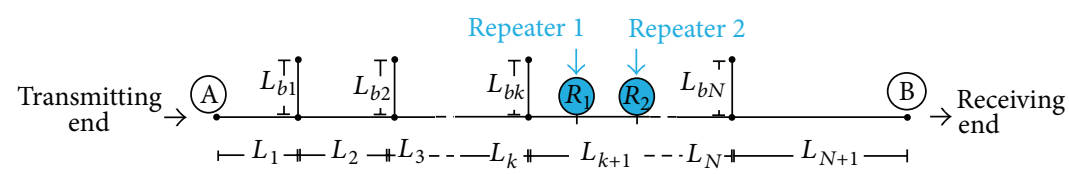

FIgURE 2: End-to-end upgraded distribution BPL connection with $N$ branches.

TABLE 1: Five indicative overhead distribution BPL topologies $[3,17,18,20]$.

\begin{tabular}{|c|c|c|c|c|}
\hline Denotation & Description & $\begin{array}{c}\text { Number } \\
\text { of } \\
\text { branches } \\
(N)\end{array}$ & Lengths of distribution TLs $\left[L_{1} \cdots L_{N+1}\right]$ & $\begin{array}{l}\text { Lengths of branch TLs } \\
\qquad\left[L_{b 1} \cdots L_{b N}\right]\end{array}$ \\
\hline Overhead urban case A & A typical urban topology & 3 & [500 m $200 \mathrm{~m} 100 \mathrm{~m} 200 \mathrm{~m}]$ & {$[8 \mathrm{~m} 13 \mathrm{~m} 10 \mathrm{~m}]$} \\
\hline Overhead urban case B & An aggravated urban topology & 5 & [ $200 \mathrm{~m} 50 \mathrm{~m} 100 \mathrm{~m} 200 \mathrm{~m} 300 \mathrm{~m} 150 \mathrm{~m}]$ & {$[12 \mathrm{~m} 5 \mathrm{~m} 28 \mathrm{~m} 41 \mathrm{~m} 17 \mathrm{~m}]$} \\
\hline Overhead suburban case & A typical suburban topology & 2 & {$[500 \mathrm{~m} 400 \mathrm{~m} 100 \mathrm{~m}]$} & {$[50 \mathrm{~m} 10 \mathrm{~m}]$} \\
\hline Overhead rural case & A typical rural topology & 1 & {$[600 \mathrm{~m} 400 \mathrm{~m}]$} & {$[300 \mathrm{~m}]$} \\
\hline Overhead "LOS" case & "LOS" transmission & 0 & {$[1000 \mathrm{~m}]$} & - \\
\hline
\end{tabular}

wireless channels. Note that these five indicative overhead distribution BPL topologies are common to both overhead $\mathrm{MV} / \mathrm{BPL}$ and overhead LV/BPL networks [3].

Similarly to overhead distribution BPL case, five indicative underground distribution BPL topologies concerning average $200 \mathrm{~m}$ long end-to-end connections, which are detailed in Table 2, are also examined in this paper, namely, (i) urban case A, (ii) urban case B, (iii) underground suburban case, (iv) underground rural case, and (v) underground "LOS" transmission along the same end-to-end distance $L=L_{1}+\cdots+L_{N+1}=200 \mathrm{~m}$. Again, note that these five indicative underground distribution BPL topologies are common to both underground $\mathrm{MV} / \mathrm{BPL}$ and underground LV/BPL networks [3].

During the following analysis, the distribution BPL topology of Figure 2, having $N$ branches and multiple repeaters, is considered. In order to simplify the following analysis without affecting its generality, the branching TLs are assumed identical to the distribution TLs, and the interconnections between the distribution and branch conductors are fully activated. In addition, the transmitting and the receiving ends are assumed matched to the characteristic impedance of distribution TLs, whereas the branch terminations are assumed open circuits. These topological and circuital parameters of the indicative distribution BPL topologies are detailed in $[1,3,16-28,34,38-43]$.

\section{Modal Analysis of Distribution BPL Networks}

3.1. The Modal Propagation Analysis. As it has already been analyzed in $[1,3,13,16-23,29,34,35,44,45]$, through a matrix approach, the standard TL analysis can be extended to the MTL case, which involves more than two conductors. Compared to a two-conductor line supporting one forwardand one backward-traveling wave, an MTL structure with $n+$ 1 conductors parallel to the $z$ axis, as depicted in Figures 1(a)1(d), may support $n$ pairs of forward- and backward-traveling waves with corresponding propagation constants. Each pair of forward- and backward-traveling waves is referred to as a mode. In the case of distribution MTL configurations presented in Figures 1(a)-1(d) and examined in this paper, distribution $\mathrm{MV} / \mathrm{BPL}$ and $\mathrm{LV} / \mathrm{BPL}$ MTL structures may support three $(n=3)$ and four $(n=4)$ modes, respectively.

As it has already been presented in $[1,3,13,16-23$, $29,34,35,44,45]$, the hybrid method models the spectral relationship between $V_{i}^{m}(z), i=1, \ldots, n$ and $V_{j}^{m}(0), j=$ $1, \ldots, n$ proposing operators $H_{i, j}^{m}\{\cdot\}, i, j=1, \ldots, n$ so that

$$
\mathbf{V}^{m}(z)=\mathbf{H}^{m}\left\{\mathbf{V}^{m}(0)\right\}
$$

where $\mathbf{V}^{m}(z)=\left[V_{1}^{m}(z) \cdots V_{n}^{m}(z)\right]^{T}$ are the modal voltages of the $n$ modes supported by the distribution BPL configuration considered, [.] $]^{T}$ denotes the transpose of a matrix, $\mathbf{H}^{m}\{\cdot\}$ is the $n \times n$ modal transfer function matrix whose elements $H_{i, j}^{m}\{\cdot\}, i, j=1, \ldots, n$ are the modal transfer functions, and $H_{i, j}^{m}$ denotes the element of matrix $\mathbf{H}^{m}\{\cdot\}$ in row $i$ of column $j$.

3.2. Coupling Schemes. According to how signals are injected onto overhead and underground distribution BPL transmission lines, two different coupling schemes exist $[18,22,23$, 25, 26]: (i) WtG or StP coupling schemes when the signal is injected onto one conductor and returns via the ground or the shield for overhead or underground distribution BPL connections, respectively, WtG or StP coupling between conductor $s$ and ground or shield will be denoted as $\mathrm{WtG}^{s}$ or $\mathrm{StP}^{s}$, respectively; (ii) WtW or PtP coupling schemes when the signal is injected between two conductors for overhead or underground distribution BPL connections, respectively. WtW or PtP coupling between conductors $p$ and $q$ will be denoted as $\mathrm{WtW}^{p-q}$ or $\mathrm{PtP}^{p-q}$, respectively.

Based on (1), the coupling transfer function $H^{X}\{\cdot\}$ is given from

$$
H^{X}\{\cdot\}=\left[\mathbf{C}^{X}\right]^{T} \cdot \mathbf{T}_{V} \cdot \mathbf{H}^{m}\{\cdot\} \cdot \mathbf{T}_{V}^{-1} \cdot \mathbf{C}^{X},
$$


TABLE 2: Five indicative underground distribution BPL topologies $[3,16,20]$.

\begin{tabular}{|c|c|c|c|c|}
\hline Denotation & Description & $\begin{array}{c}\text { Number } \\
\text { of } \\
\text { branches } \\
(N)\end{array}$ & $\begin{array}{l}\text { Lengths of distribution TLs } \\
\qquad\left[L_{1} \cdots L_{N+1}\right]\end{array}$ & $\begin{array}{l}\text { Lengths of branch TLs } \\
\qquad\left[L_{b 1} \cdots L_{b N}\right]\end{array}$ \\
\hline Underground urban case A & A typical urban topology & 3 & {$[70 \mathrm{~m} 55 \mathrm{~m} 45 \mathrm{~m} 30 \mathrm{~m}]$} & {$[12 \mathrm{~m} 7 \mathrm{~m} 21 \mathrm{~m}]$} \\
\hline Underground urban case B & $\begin{array}{c}\text { An aggravated urban } \\
\text { topology }\end{array}$ & 5 & {$[40 \mathrm{~m} 10 \mathrm{~m} 20 \mathrm{~m} 40 \mathrm{~m} 60 \mathrm{~m} 30 \mathrm{~m}]$} & [22 m $12 \mathrm{~m} 8 \mathrm{~m} 2 \mathrm{~m} 17 \mathrm{~m}$ ] \\
\hline Underground suburban case & A typical suburban topology & 2 & {$[50 \mathrm{~m} 100 \mathrm{~m} 50 \mathrm{~m}]$} & {$[60 \mathrm{~m} 30 \mathrm{~m}]$} \\
\hline Underground rural case & A typical rural topology & 1 & {$[50 \mathrm{~m} 150 \mathrm{~m}]$} & {$[100 \mathrm{~m}]$} \\
\hline Underground "LOS" case & "LOS" transmission & 0 & {$[200 \mathrm{~m}]$} & - \\
\hline
\end{tabular}

where $[\cdot]^{X}$ denotes the applied coupling scheme, $\mathbf{C}^{X}$ is the $n \times 1$ coupling column vector detailed in [3], and $\mathbf{T}_{V}$ is a $n \times n$ matrix depending on the distribution power grid type-either overhead or underground, either MV or LVthe frequency, the physical properties of the cables used, and the geometry of the MTL configuration $[3,5,10,12,13,18,23$, $24,37,46-50]$.

\section{Noise, EMI Regulations, and Capacity of Distribution BPL Networks}

4.1. Noise Characteristics. As it has already been mentioned in $[10,13,18,20,25,26,28,51-55]$, colored background noise and impulsive noise are the dominant types in overhead and underground MV/BPL and LV/BPL networks.

As it regards the noise properties of distribution BPL networks in the $3-88 \mathrm{MHz}$ frequency range, a uniform additive white Gaussian noise (AWGN) is assumed. Its power spectral density (PSD) levels $N(f)$ are equal to $-105 \mathrm{dBm} / \mathrm{Hz}$ and $-135 \mathrm{dBm} / \mathrm{Hz}$ for overhead and underground distribution BPL networks, respectively $[9,10,18,20,25,26,28,52,53,56]$.

\subsection{Electromagnetic Compatibility (EMC) of Distribution BPL} Networks with Other Radio Services. To regulate EMI of distribution BPL networks to other already existing communications systems in the same frequency band of operation, appropriate power constraints are imposed.

The injected PSD limits (IPSD limits) proposed by Ofcom for compliance with FCC Part 15-analytically presented in [57-59] - are adopted in this paper, namely:

(i) in the 3-30 MHz frequency range, maximum levels of $-60 \mathrm{dBm} / \mathrm{Hz}$ and $-40 \mathrm{dBm} / \mathrm{Hz}$ constitute appropriate IPSD limits $p_{\text {con }}$ for overhead and underground distribution BPL networks, respectively

(ii) in the $30-88 \mathrm{MHz}$ frequency range, maximum IPSD limits $p_{\text {con }}$ are equal to $-77 \mathrm{dBm} / \mathrm{Hz}$ and $-57 \mathrm{dBm} / \mathrm{Hz}$ for overhead and underground distribution BPL networks, respectively.

These power constraints provide a presumption of compliance with the current FCC Part 15 limits [18, 20, 58]. Repeater Systems under Fixed EMI Limits. Capacity is the maximum achievable transmission rate over a BPL channel and depends on the power grid type, power grid topology, applied coupling scheme, MTL configuration, noise characteristics, and imposed EMI limits. Extending the definition of capacity, cumulative capacity is defined as the cumulative upper bound of information that can be reliably transmitted over a BPL channel.

In the light of information theory $[9-15,18,20]$ and with reference to Figure 2, in the case of conventional distribution BPL topologies, their overall capacity $C$, which is the end-toend capacity from $\mathrm{A}$ to $\mathrm{B}$, is determined from

$$
\begin{aligned}
C & =C_{\mathrm{A} \rightarrow \mathrm{B}} \\
& =f_{s} \sum_{q=0}^{\mathrm{Q}-1} \log _{2}\left\{1+\left[\frac{\left\langle p_{\text {con }}\left(q f_{s}\right)\right\rangle_{L}}{\left\langle N\left(q f_{s}\right)\right\rangle_{L}} \cdot\left|H^{X}\left(q f_{s}\right)\right|^{2}\right]\right\},
\end{aligned}
$$

where $[\cdot]_{\mathrm{A} \rightarrow \mathrm{B}}$ defines the transmitting $(\mathrm{A})$ and receiving $(\mathrm{B})$ end points, $\langle\cdot\rangle_{L}$ is an operator that converts $\mathrm{dBm} / \mathrm{Hz}$ into a linear power ratio $(\mathrm{W} / \mathrm{Hz}), Q$ is the number of subchannels in the BPL signal frequency range of interest, and $f_{s}$ is the flat-fading subchannel frequency spacing.

To investigate the capacity impact of multihop repeater systems installation, first, with reference to Figure 2, let us assume that a two-hop repeater system is deployed across an end-to-end distribution BPL topology; its sole repeater is installed at distance $R_{1}$ from the transmitting end. Hence, the initial distribution BPL topology is divided into two new distribution BPL connections. Due to the bus-bar concatenation of these two connections and taking into account (3), the new overall capacity $C^{\prime}$ of the distribution BPL topology with twohop repeater system is determined as the minimum value of the capacities of these two connections:

$$
C^{\prime}=\min \left\{C_{\mathrm{A} \rightarrow R_{1}}, C_{R_{1} \rightarrow \mathrm{B}}\right\}
$$

where $\min \{x, y\}$ returns the smallest value between either $x$ or $y$.

Similar to two-hop repeater systems case, with reference to Figure 2, when a three-hop repeater system is deployed across a distribution BPL topology, two repeaters are installed across its end-to-end transmission path at distances $R_{1}$ and $R_{2}$, respectively. Thus, the conventional distribution $\mathrm{BPL}$ topology is divided into three new distribution BPL connections. The new overall capacity $C^{\prime \prime}$ of the upgraded 
distribution BPL topology is determined as the minimum value of the capacities of these three connections:

$$
C^{\prime \prime}=\min \left\{C_{\mathrm{A} \rightarrow R_{1}}, C_{R_{1} \rightarrow R_{2}}, C_{R_{2} \rightarrow \mathrm{B}}\right\} .
$$

\section{Numerical Results and Discussion}

The simulations of various types of overhead and underground MV/BPL and LV/BPL topologies with multihop repeater systems aim at investigating their broadband capacity potential and how their capacity performance in the 3$88 \mathrm{MHz}$ frequency band is affected by certain factors, such as distribution power grid type, distribution BPL topology, coupling scheme, and number of repeaters.

As it is usually done to simplify the analysis without, however, harming its generality $[3,13,16,21,22]$, in the case of overhead and underground MV/BPL networks, among the possible $3 \mathrm{WtG} / \mathrm{StP}$ and $6 \mathrm{WtW} / \mathrm{PtP}$ scheme configurations per each MV distribution power grid type, only $\mathrm{WtG}^{1} / \mathrm{StP}^{1}$ and $\mathrm{WtW}^{1-2} / \mathrm{PtP}^{1-2}$ coupling schemes will be applied, hereafter. Similarly, in the case of overhead and underground $\mathrm{LV} / \mathrm{BPL}$ networks, among the possible $4 \mathrm{WtG} / \mathrm{StP}$ and $12 \mathrm{WtW} / \mathrm{PtP}$ scheme configurations per each LV distribution power grid type, only $\mathrm{WtG}^{1} / \mathrm{StP}^{1}$ and $\mathrm{WtW}^{1-2} / \mathrm{PtP}^{1-2}$ coupling schemes will be applied, hereafter. This selection of representative coupling schemes is made according to their favorable capacity characteristics $[3,13,22,23]$.

\subsection{Broadband Capacity Performance of Conventional Distri-} bution BPL Topologies. In order to understand the significant capacity impact of installing multihop repeater systems, first, there is need of recognizing the inherent capacity capabilities of conventional distribution BPL topologies.

In Figures 3(a) and 3(b), the cumulative capacity is plotted versus frequency for the five indicative overhead MV/BPL topologies when $\mathrm{WtG}^{1}$ and $\mathrm{WtW}^{1-2}$ coupling schemes are applied, respectively. In Figures 3(c) and 3(d), similar curves are given in the case of indicative underground MV/BPL topologies when $\mathrm{StP}^{1}$ and $\mathrm{PtP}^{1-2}$ coupling schemes are deployed, respectively. In Figures 4(a)-4(d), similar plots are drawn in the case of indicative distribution LV/BPL topologies. In Table 3, a synopsis of these simulation results concerning overall capacity $C$ of conventional distribution BPL topologies for different distribution power grid types, indicative BPL topologies, and coupling schemes is reported.

Observing Figures 3(a)-3(d), 4(a)-4(d), and Table 3, it is evident that the broadband capacity behavior of distribution BPL topologies highlights their established role either as broadband last mile alternative or as SG partner solution $[3,7,18,20]$. Despite these favourable capacity resultsranging from $378 \mathrm{Mbps}$ to approximately $2.2 \mathrm{Gbps}$ - the overall capacity drastically depends on the distribution power grid type, the number/length of the branches encountered along the end-to-end transmission path, noise properties, and imposed EMI regulations [18, 20]. In accordance with the picture obtained from their capacity behavior, the general BPL class taxonomy- "LOS," good, and bad class, see Figures 3(a) $-3(d)$ and 4(a) $-4(d)$-remains the same in distribution
BPL topologies even in terms of capacity [17-22]. Actually, the capacity differences between adjacent BPL classes are significant, being of the order of approximately 100-200 Mbps.

Due to the bus-bar nature of distribution BPL networks, the aggravated topologies of BPL networks critically deteriorate the overall network capacity. This network capacity degradation hinders further BPL systems symbiosis with other telecommunications systems [17-22].

\subsection{Broadband Capacity Performance of Distribution BPL} Topologies with Two-Hop Repeater Systems. The additive deployment of two-hop repeater systems across conventional distribution BPL networks offers additional degrees of capacity flexibility so that different distribution BPL networks may easily intraoperate as well as interoperate that is, BPL systems cooperation with other well-validated broadband technologies.

More specifically, the capacity contribution of two-hop repeater systems is mainly concentrated on the mitigation of capacity differences due to (i) different distribution power grid types, (ii) different topologies, and (iii) different coupling schemes. Therefore, with reference to Figure 2 and taking into account the need of scalable capacities among various distribution BPL networks, the appropriate installation position of the sole repeater of a two-hop repeater system across endto-end transmission paths of more aggravated distribution BPL topologies defines a low-cost and quick solution against the aforementioned causes of capacity discrepancies and performance degradation.

In Figures 5(a) and 5(b), the overall capacity $C^{\prime}$ of overhead MV/BPL topologies with two-hop repeater systems is plotted versus the repeater distance from the transmitting end for the aforementioned indicative topologies when $\mathrm{WtG}^{1}$ and $\mathrm{WtW}^{1-2}$ coupling schemes are applied, respectively. In Figures 5(c) and 5(d), similar curves are plotted in the case of indicative underground MV/BPL topologies when $\mathrm{StP}^{1}$ and $\mathrm{PtP}^{1-2}$ coupling schemes are employed, respectively. In Figures 6(a)-6(d), similar plots are drawn in the case of distribution LV/BPL topologies.

From Figures 5(a)-5(d) and 6(a)-6(d), it is obvious that the additive insertion of two-hop repeater systems across conventional distribution BPL topologies improves their initial overall capacities regardless of the BPL topology and coupling scheme applied. Actually, in Table 4, the maximum overall capacity of each indicative distribution BPL topology with two-hop repeater system is reported as well as its corresponding repeater distance from the transmitting end when different coupling schemes are applied.

Observing Table 4, it is demonstrated that the capacity increase due to the integration of two-hop repeater systems is critical. Since the design of high-bitrate distribution BPL networks imposes strict common capacity thresholds across the overall distribution BPL networks and their corresponding bus-bar-concatenated distribution BPL topologies, two-hop repeater systems offer the necessary capacity boost especially for the bad class topologies.

As it has already been presented for channel attenuation characteristics in $[3,13,20]$ and also verified from Table 4 , 


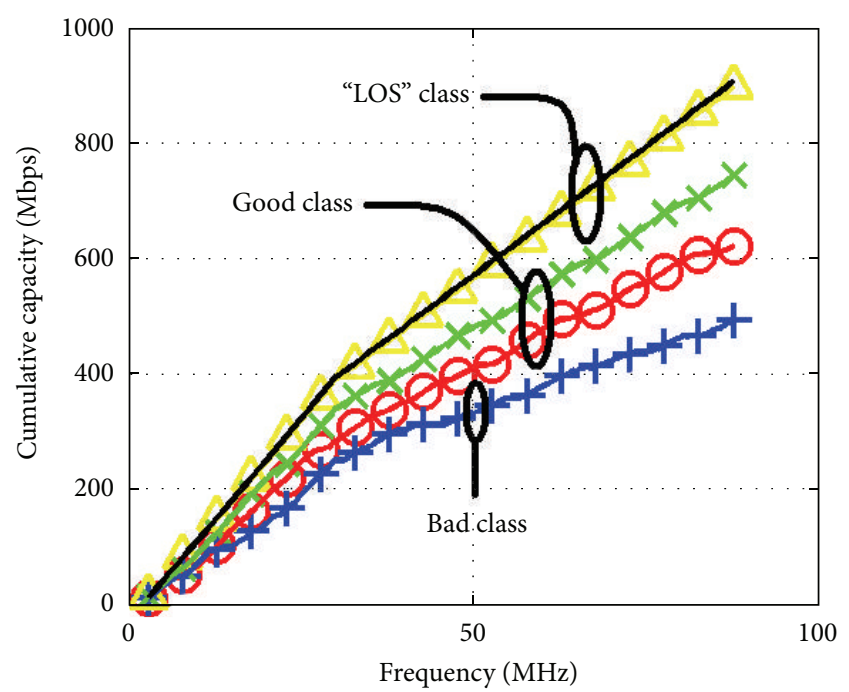

(a) Overhead/WtG ${ }^{1}$

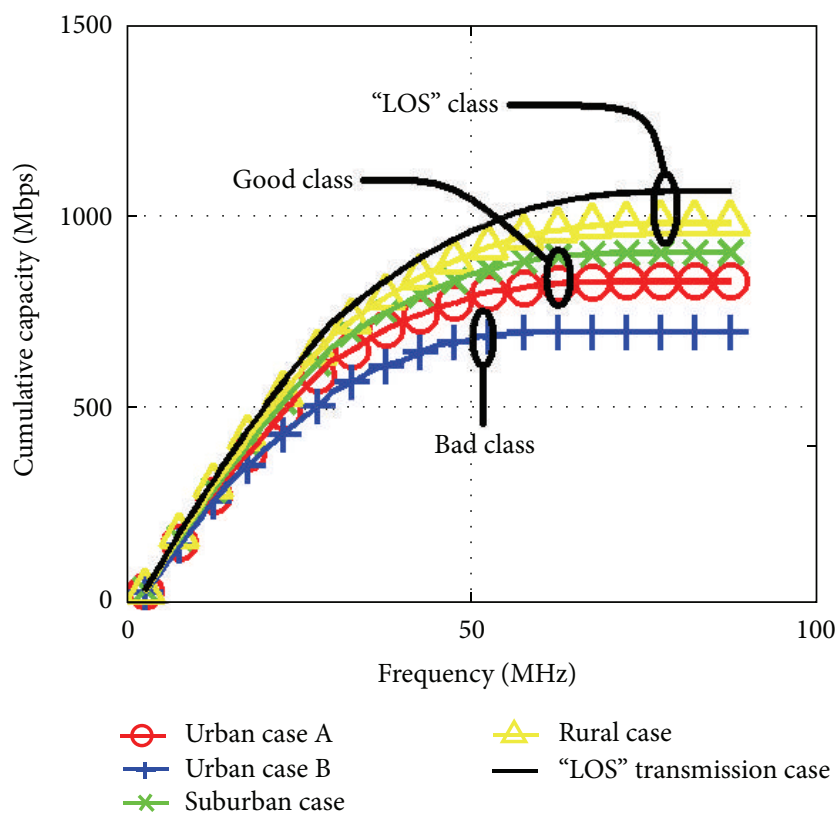

(c) Underground/StP ${ }^{1}$

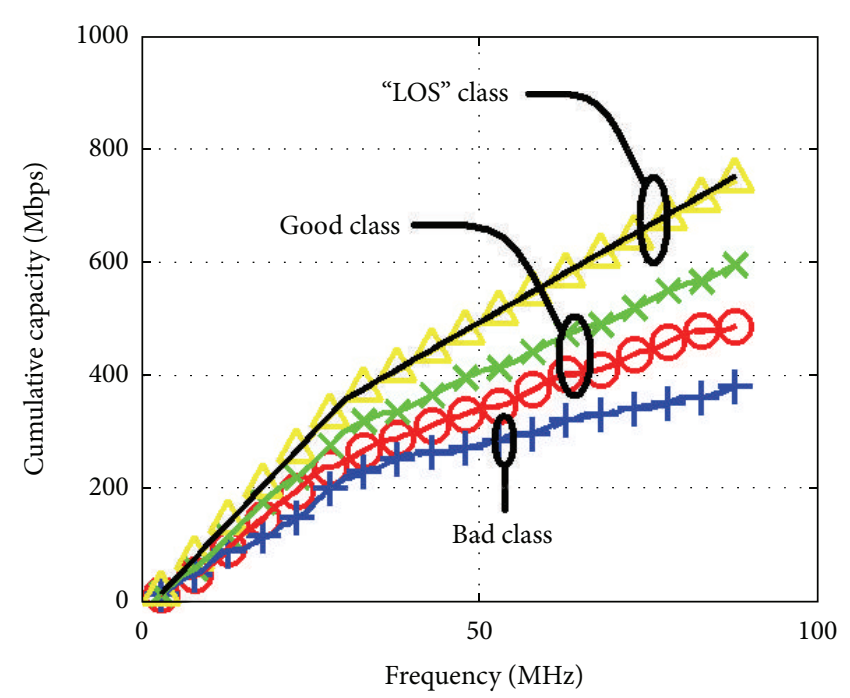

(b) Overhead/ $\mathrm{WtW}^{1-2}$

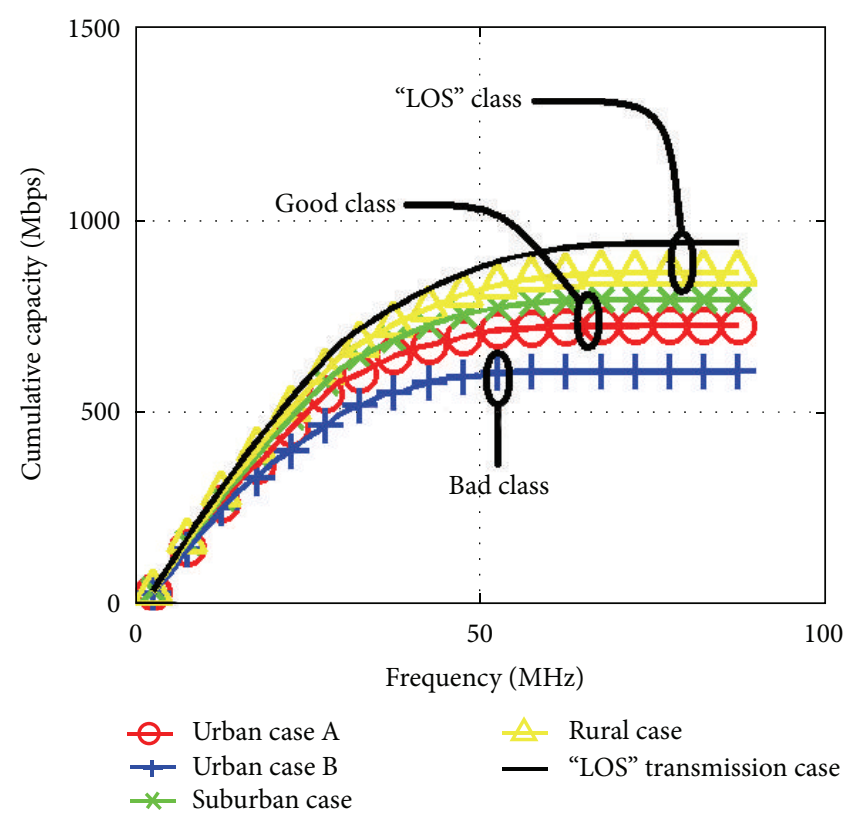

(d) Underground $/ \mathrm{PtP}^{1-2}$

FIGURE 3: Cumulative capacity of the five indicative topologies of conventional MV/BPL networks in the 3-88 MHz frequency band when different coupling schemes are applied.

WtG/StP coupling schemes attain more favourable results in terms of transmission and capacity metrics in comparison with the respective WtW/PtP ones. However, the significant $\mathrm{EMI}$ of WtG/StP coupling schemes to other already licensed wireless communications is their main drawback. Anyway, today's EMI regulations provide the required protection of BPL operation against other radioservices. Through the deployment of two-hop repeater systems, apart from the mitigation of capacity differences among different topologies, significant capacity divergences may be mitigated when different coupling schemes and EMC requirements occur. More specifically, in order to satisfy strict EMI regulations that are locally and/or periodically imposed, $\mathrm{WtG} / \mathrm{StP}$ topologies may be equivalently alternated by their respective WtW/PtP topologies when two-hop repeater systems are studiously installed in the latter cases. Hence, interesting capacity tradeoffs among coupling schemes, different EMI regulations, and distribution BPL topologies with two-hop repeater systems can further be defined.

\subsection{Broadband Capacity Performance of Distribution BPL} Topologies with Three-Hop Repeater Systems. The urgent need of cooperative communications among distribution BPL networks and other overhead and underground HV/BPL, 


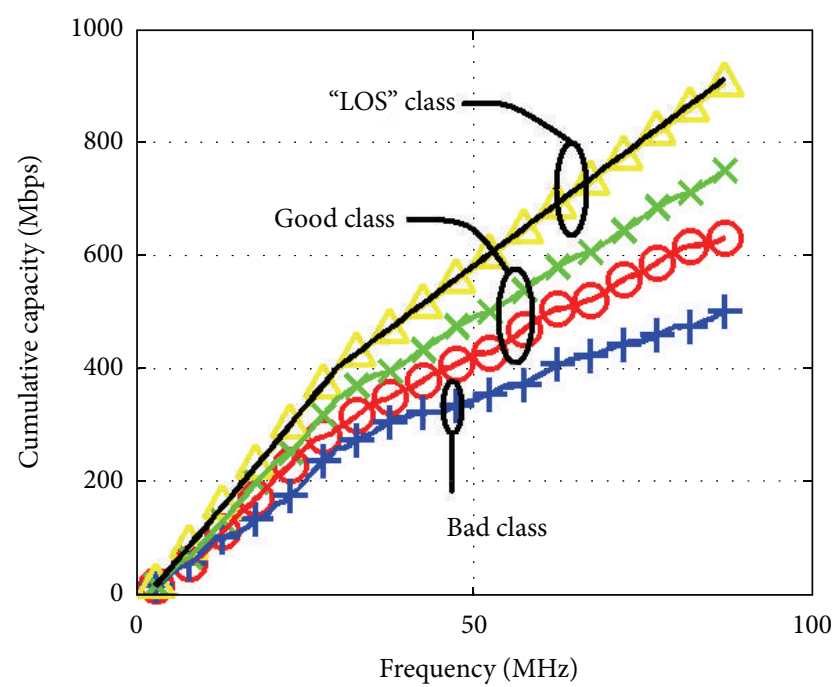

(a)

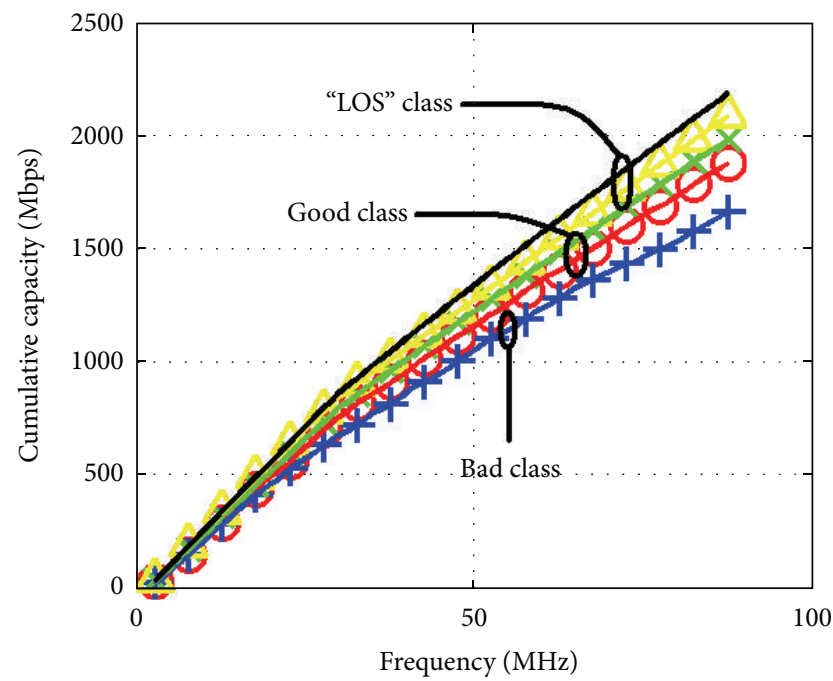

(c)

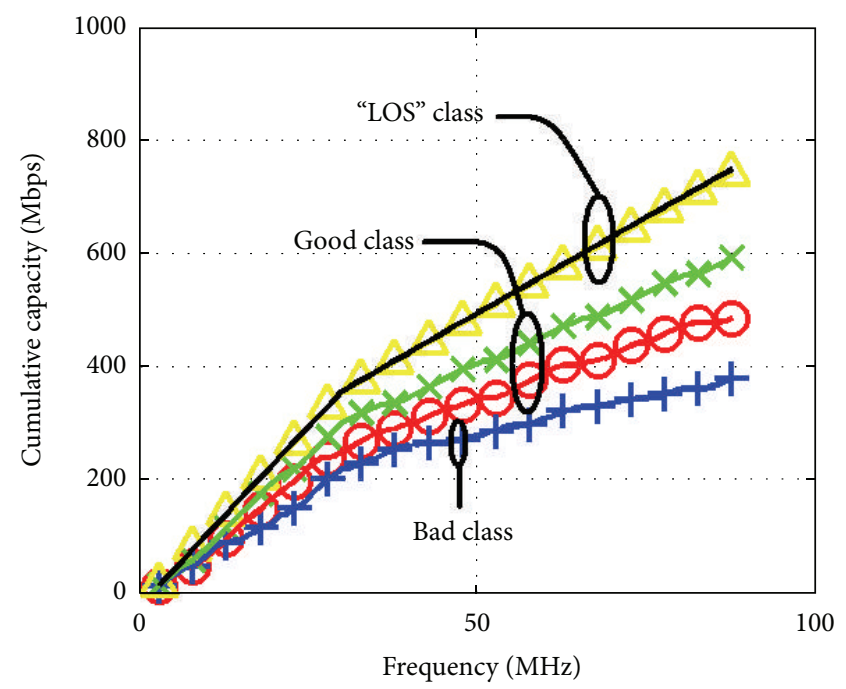

(b)

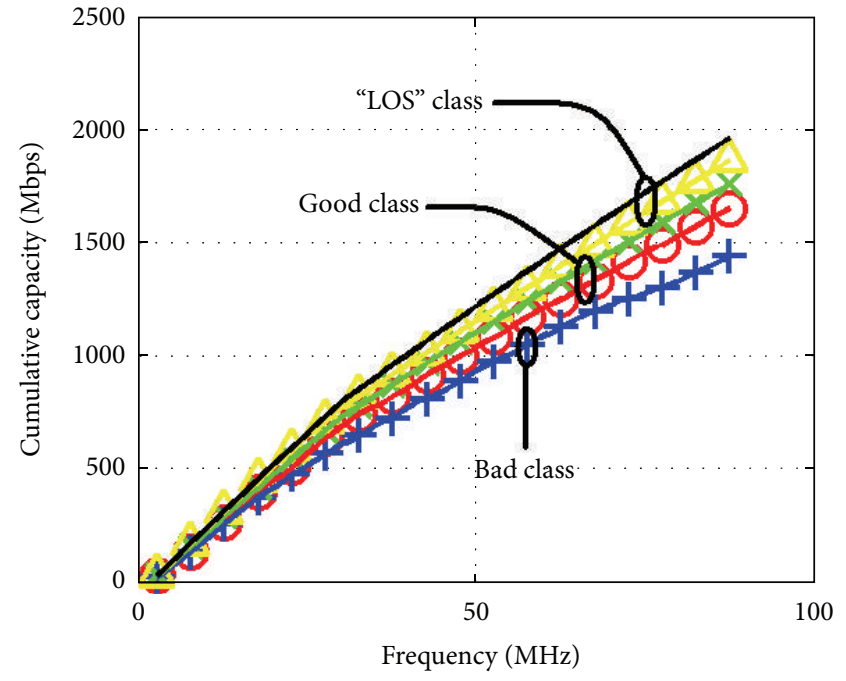

(d)

FIGURE 4: Same as in Figure 3 but for conventional overhead and underground LV/BPL networks.

TABLE 3: Overall capacity of conventional distribution BPL networks (OV: overhead; UN: underground).

\begin{tabular}{|c|c|c|c|c|c|c|}
\hline & & $\begin{array}{c}\text { Urban case A } \\
\text { Capacity } \\
\text { (Mbps) }\end{array}$ & $\begin{array}{c}\text { Urban case B } \\
\text { Capacity } \\
\text { (Mbps) }\end{array}$ & $\begin{array}{c}\text { Suburban case } \\
\text { Capacity } \\
\text { (Mbps) }\end{array}$ & $\begin{array}{c}\text { Rural case } \\
\text { Capacity } \\
\text { (Mbps) }\end{array}$ & $\begin{array}{c}\text { "LOS" case } \\
\text { Capacity } \\
\text { (Mbps) }\end{array}$ \\
\hline \multirow{2}{*}{ OVMV } & $\mathrm{WtG}^{1}$ & 621 & 493 & 743 & 895 & 905 \\
\hline & $\mathrm{WtW}^{1-2}$ & 485 & 378 & 594 & 743 & 750 \\
\hline \multirow{2}{*}{ UNMV } & $\mathrm{StP}^{1}$ & 831 & 700 & 906 & 982 & 1066 \\
\hline & $\mathrm{PtP}^{1-2}$ & 714 & 595 & 782 & 851 & 928 \\
\hline \multirow{2}{*}{ OVLV } & $\mathrm{WtG}^{1}$ & 633 & 502 & 752 & 906 & 912 \\
\hline & $\mathrm{WtW}^{1-2}$ & 485 & 378 & 593 & 741 & 749 \\
\hline \multirow{2}{*}{ UNLV } & $\mathrm{StP}^{1}$ & 1870 & 1656 & 1974 & 2078 & 2179 \\
\hline & $\mathrm{PtP}^{1-2}$ & 1652 & 1440 & 1758 & 1863 & 1961 \\
\hline
\end{tabular}




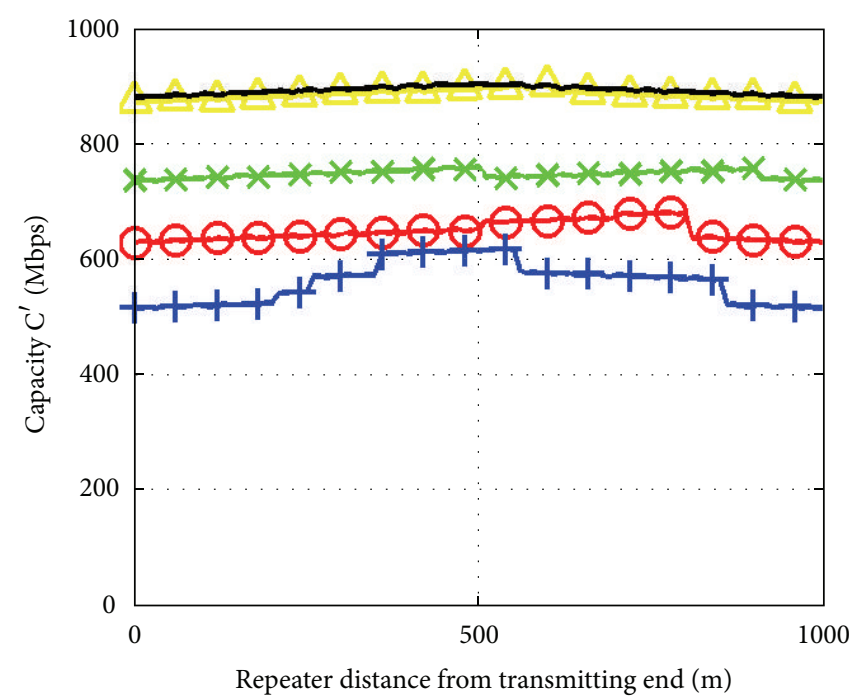

(a) Overhead/WtG

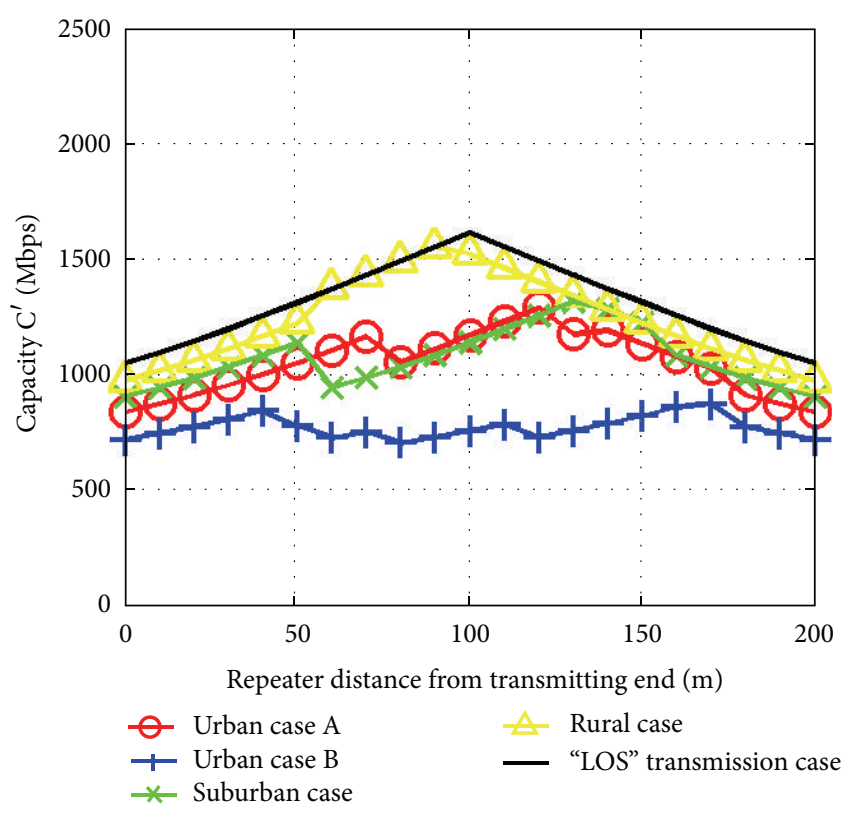

(c) Underground $/ \mathrm{StP}^{1}$

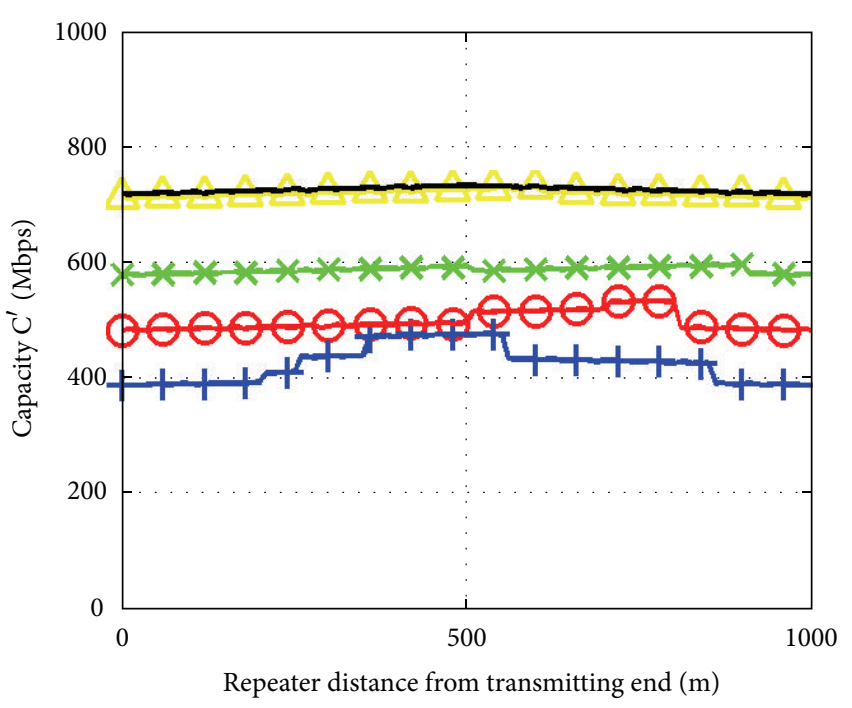

(b) Overhead/WtW $\mathrm{W}^{1-2}$

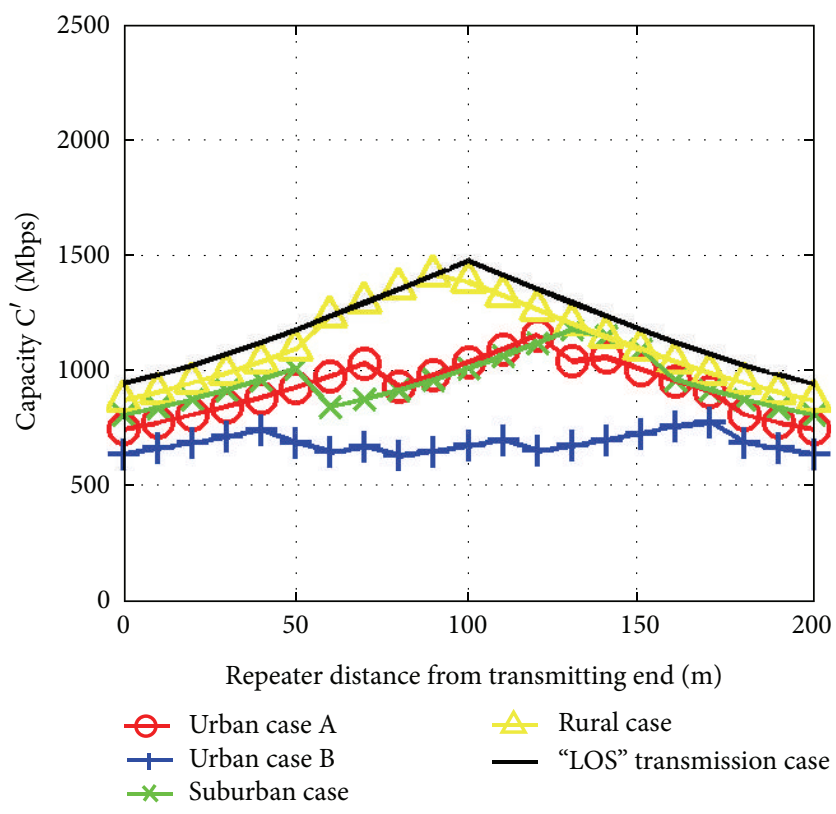

(d) Underground/PtP ${ }^{1-2}$

FIGURE 5: Overall capacity of distribution MV/BPL topologies with two-hop repeater systems for the five indicative topologies versus repeater distance from point A-see Figure 2-when different coupling schemes are applied.

MV/BPL, and LV/BPL networks under the umbrella of a unified SG environment demands the guarantee of scalable capacities. Although two-hop repeater systems offer significant capacity leverage, their capacity contribution still remains marginal and asthenic.

The adoption of three-hop repeater systems delivers the amount of extra capacity that contributes to more relaxed symbiosis among different distribution BPL networks, thus, better satisfying scalable capacity goals. At the same time, the additional cost of deploying one additional repeater in comparison with the overall installation cost of two-hop repeater systems does not become prohibitive.
With reference to Figure 2, the appropriate installation positions of the two repeaters of a three-hop repeater system across the end-to-end transmission paths of distribution BPL topologies may define a convenient and more capacityresultful solution to capacity losses due to different power grid types, topologies, and coupling schemes. The capacity performance analysis of upgraded distribution BPL topologies with three-hop repeater systems is studied through the first proposed capacity contour plots; capacity contour plot is defined as a curve connecting repeater installation points where the capacity has the same particular value. When the plots are close together, the capacity variation is steep. 


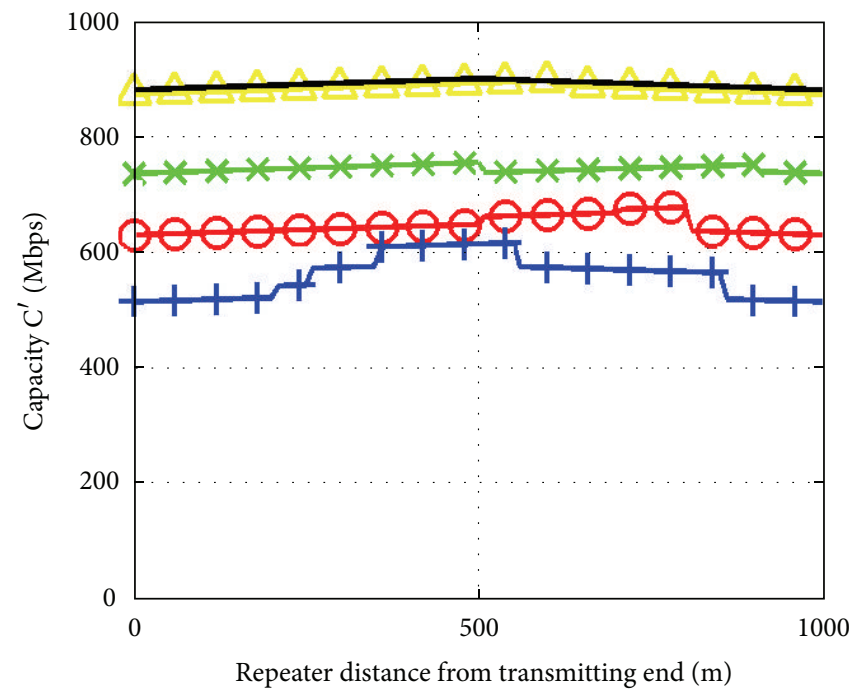

(a)

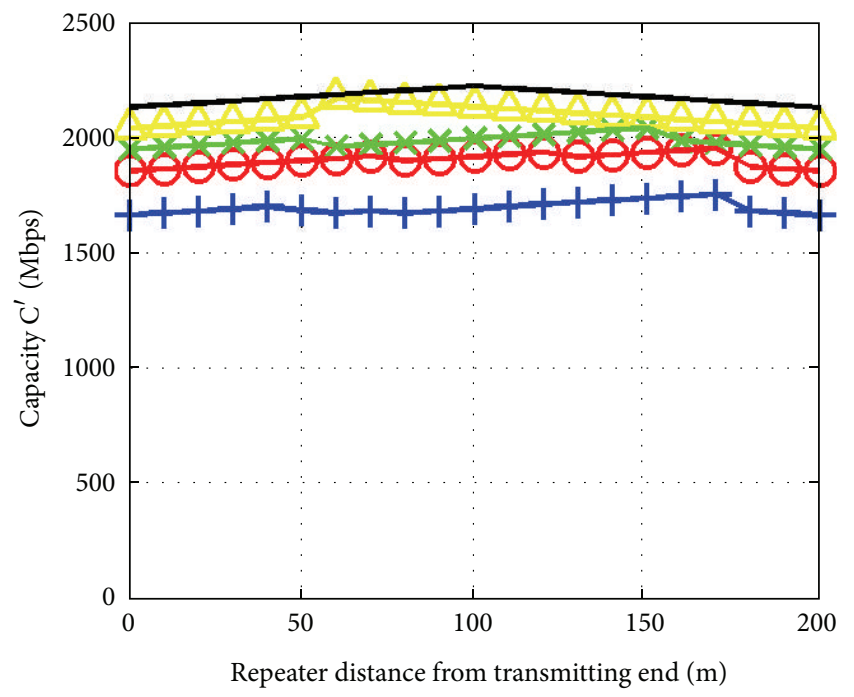

(c)

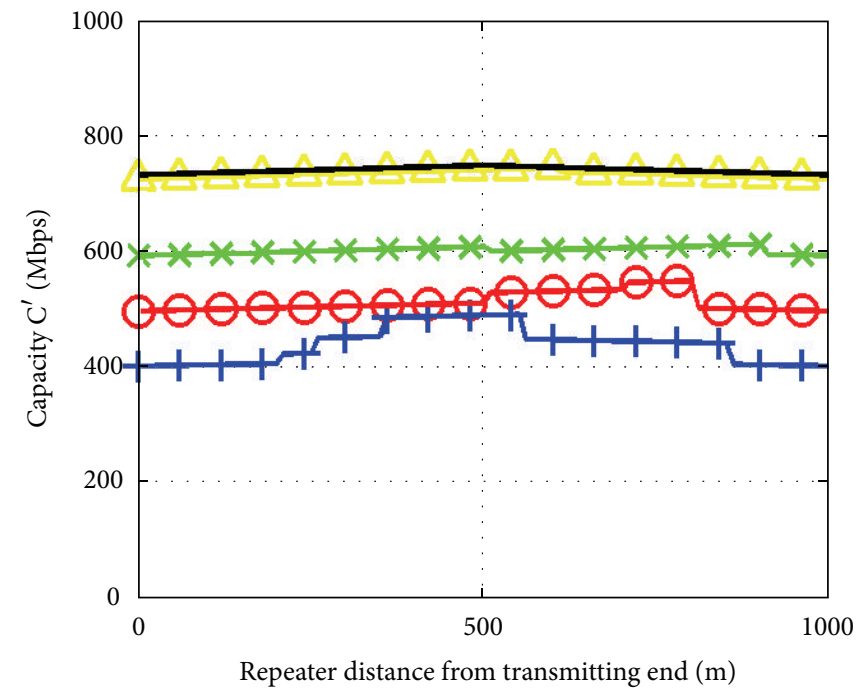

(b)

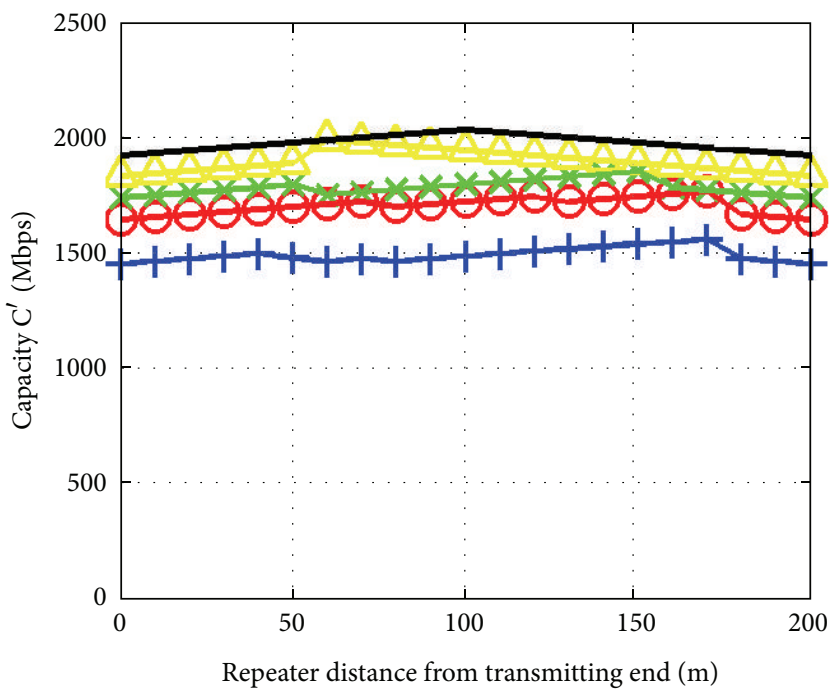

(d)

FIgURE 6: Same as in Figure 5 but for overhead and underground LV/BPL topologies with two-hop repeater systems.

TABLE 4: Overall capacity of distribution BPL topologies with two-hop repeater systems (OV: overhead; UN: underground).

\begin{tabular}{|c|c|c|c|c|c|c|c|c|c|c|c|}
\hline & & \multicolumn{2}{|c|}{ Urban case A } & \multicolumn{2}{|c|}{ Urban case B } & \multicolumn{2}{|c|}{ Suburban case } & \multicolumn{2}{|c|}{ Rural case } & \multicolumn{2}{|c|}{ "LOS" case } \\
\hline & & $\begin{array}{c}\text { Capacity } \\
\text { (Mbps) }\end{array}$ & $\begin{array}{c}\text { Repeater } \\
\text { distance } \\
(\mathrm{m})\end{array}$ & $\begin{array}{c}\text { Capacity } \\
\text { (Mbps) }\end{array}$ & $\begin{array}{c}\text { Repeater } \\
\text { distance } \\
(\mathrm{m})\end{array}$ & $\begin{array}{c}\text { Capacity } \\
\text { (Mbps) }\end{array}$ & $\begin{array}{c}\text { Repeater } \\
\text { distance } \\
(\mathrm{m})\end{array}$ & $\begin{array}{c}\text { Capacity } \\
\text { (Mbps) }\end{array}$ & $\begin{array}{c}\text { Repeater } \\
\text { distance } \\
(\mathrm{m})\end{array}$ & $\begin{array}{c}\text { Capacity } \\
\text { (Mbps) }\end{array}$ & $\begin{array}{c}\text { Repeater } \\
\text { distance } \\
(\mathrm{m})\end{array}$ \\
\hline \multirow{2}{*}{ OVMV } & $\mathrm{WtG}^{1}$ & 672 & 780 & 601 & 530 & 760 & 500 & 918 & 600 & 922 & 500 \\
\hline & $\mathrm{WtW}^{1-2}$ & 537 & 780 & 475 & 530 & 607 & 900 & 757 & 590 & 761 & 500 \\
\hline \multirow{2}{*}{ UNMV } & $\mathrm{StP}^{1}$ & 1333 & 120 & 872 & 170 & 1362 & 130 & 1626 & 90 & 1693 & 100 \\
\hline & $\mathrm{PtP}^{1-2}$ & 1164 & 120 & 746 & 170 & 1193 & 130 & 1456 & 90 & 1523 & 100 \\
\hline \multirow{2}{*}{ OVLV } & $\mathrm{WtG}^{1}$ & 679 & 800 & 610 & 550 & 766 & 500 & 924 & 600 & 928 & 500 \\
\hline & $\mathrm{WtW}^{1-2}$ & 538 & 800 & 474 & 550 & 608 & 900 & 756 & 600 & 761 & 500 \\
\hline \multirow{2}{*}{ UNLV } & $\mathrm{StP}^{1}$ & 1959 & 170 & 1739 & 170 & 2058 & 150 & 2201 & 60 & 2258 & 100 \\
\hline & $\mathrm{PtP}^{1-2}$ & 1773 & 170 & 1541 & 170 & 1866 & 150 & 2017 & 60 & 2067 & 100 \\
\hline
\end{tabular}


TABle 5: Maximum Overall Capacity of Distribution BPL Topologies with Three-Hop Repeater Systems (OV: Overhead; UN: Underground).

\begin{tabular}{|c|c|c|c|c|c|c|c|c|c|c|c|}
\hline & & \multicolumn{2}{|c|}{ Urban case A } & \multicolumn{2}{|c|}{ Urban case B } & \multicolumn{2}{|c|}{ Suburban case } & \multicolumn{2}{|c|}{ Rural case } & \multicolumn{2}{|c|}{ "LOS" case } \\
\hline & & $\begin{array}{c}\text { Capacity } \\
\text { (Mbps) }\end{array}$ & $\begin{array}{l}\text { Repeaters } \\
\text { distance } \\
{[\mathrm{A}, \mathrm{B}](\mathrm{m})}\end{array}$ & $\begin{array}{c}\text { Capacity } \\
\text { (Mbps) }\end{array}$ & $\begin{array}{l}\text { Repeaters } \\
\text { distance } \\
{[\mathrm{A}, \mathrm{B}](\mathrm{m})}\end{array}$ & $\begin{array}{c}\text { Capacity } \\
\text { (Mbps) }\end{array}$ & $\begin{array}{l}\text { Repeaters } \\
\text { distance } \\
{[\mathrm{A}, \mathrm{B}](\mathrm{m})}\end{array}$ & $\begin{array}{c}\text { Capacity } \\
\text { (Mbps) }\end{array}$ & $\begin{array}{l}\text { Repeaters } \\
\text { distance } \\
{[\mathrm{A}, \mathrm{B}](\mathrm{m})}\end{array}$ & $\begin{array}{c}\text { Capacity } \\
\text { (Mbps) }\end{array}$ & $\begin{array}{l}\text { Repeaters } \\
\text { distance } \\
{[\mathrm{A}, \mathrm{B}](\mathrm{m})}\end{array}$ \\
\hline \multirow{2}{*}{ OVMV } & $\mathrm{WtG}^{1}$ & 817 & {$[790,510]$} & 736 & {$[250,360]$} & 853 & {$[900,930]$} & 926 & {$[450,640]$} & 929 & $\overline{[310,660]}$ \\
\hline & $\mathrm{WtW}^{1-2}$ & 659 & {$[790,510]$} & 580 & {$[290,630]$} & 686 & {$[900,930]$} & 764 & {$[450,640]$} & 766 & {$[330,670]$} \\
\hline \multirow{2}{*}{ UNMV } & $\mathrm{StP} \mathrm{P}^{1}$ & 1756 & {$[70,130]$} & 1728 & {$[60,120]$} & 1826 & {$[60,140]$} & 1859 & {$[60,130]$} & 1893 & {$[60,130]$} \\
\hline & $\mathrm{PtP}^{1-2}$ & 1586 & {$[70,130]$} & 1558 & {$[60,120]$} & 1656 & {$[60,140]$} & 1689 & {$[60,130]$} & 1723 & {$[60,130]$} \\
\hline \multirow{2}{*}{ OVLV } & $\mathrm{WtG}^{1}$ & 824 & {$[510,740]$} & 738 & {$[250,360]$} & 855 & {$[900,910]$} & 932 & {$[400,610]$} & 935 & {$[330,660]$} \\
\hline & $\mathrm{WtW}^{1-2}$ & 660 & {$[510,740]$} & 580 & {$[260,360]$} & 687 & {$[900,910]$} & 764 & {$[420,610]$} & 767 & {$[330,670]$} \\
\hline \multirow{2}{*}{ UNLV } & $\mathrm{StP}^{1}$ & 2175 & {$[80,130]$} & 2088 & {$[70,120]$} & 2200 & {$[60,150]$} & 2232 & {$[50,80]$} & 2289 & {$[60,130]$} \\
\hline & $\mathrm{PtP}^{1-2}$ & 1987 & {$[80,130]$} & 1901 & {$[70,120]$} & 2016 & {$[60,150]$} & 2043 & {$[50,90]$} & 2104 & {$[60,130]$} \\
\hline
\end{tabular}

In Figures 7(a)-7(e), the overall capacity contour plot of overhead MV/BPL topologies with three-hop repeater systems is given versus the repeater $\mathrm{A}$ and $\mathrm{B}$ distances from the transmitting end for the aforementioned five indicative topologies, respectively, when $\mathrm{WtG}^{1}$ coupling scheme is applied. In Figures 7(f)-7(j), similar curves are plotted when $\mathrm{WtW}^{1-2}$ coupling scheme is employed. In Figures $9(\mathrm{a})-9(\mathrm{j})$, similar plots are drawn in the case of overhead LV/BPL topologies.

In Figures 8(a)-8(e), the overall capacity contour plot of underground $\mathrm{MV} / \mathrm{BPL}$ topologies with three-hop repeater systems is plotted versus the repeater A and B distances from the transmitting end for the aforementioned five indicative topologies, respectively, when $\mathrm{StP}^{1}$ coupling scheme is applied. In Figures $8(\mathrm{f})-8(\mathrm{j})$, similar curves are given when $\mathrm{PtP}^{1-2}$ coupling scheme is applied. In Figures $10(\mathrm{a})-10(\mathrm{j})$, similar curves are plotted in the case of underground LV/BPL topologies.

Note that in Figures 7(a)-7(j), 8(a)-8(j), 9(a)-9(j), and $10(a)-10(j)$, except for the overall capacity contour plots, the maximum overall capacity of each indicative distribution BPL topology with three-hop repeater system is marked onto capacity contour plots as well as its corresponding repeaters locations from the transmitting end.

From Figures 7(a)-7(j), 8(a)-8(j), 9(a)-9(j), and 10(a)$10(j)$, it is obvious that the insertion of three-hop repeater systems critically improves the capacities of overhead and underground MV/BPL and LV/BPL topologies. Upgraded distribution BPL networks can comfortably be transformed to multi-Mbps broadband links. Indeed, in Table 5, the maximum overall capacity of each indicative overhead and underground $\mathrm{MV} / \mathrm{BPL}$ and $\mathrm{LV} / \mathrm{BPL}$ topology with threehop repeater system is reported when different coupling schemes occur. In the same table, the corresponding repeaters distances of these maximum overall capacities are also given.

From Figures 7(a)-7(j), 8(a)-8(j), 9(a)-9(j), 10(a)-10(j), and Table 5, it is clearly shown that distribution BPL topologies with three-hop repeater systems define a more spectral-efficient implementation proposal in comparison with respective conventional BPL topologies and upgraded BPL topologies with two-hop repeater systems regardless of the distribution power grid type, distribution BPL topology, and coupling scheme applied.

As it has already been mentioned, distribution BPL topologies with three-hop repeater systems are successfully assessed by the proposed 2-D sets of overall capacity contour plots whereas the respective topologies with two-hop repeater systems define a subset of these $2-\mathrm{D}$ sets: the $x$ - and $y$ axes of the corresponding contour plots. Therefore, in all the cases examined, three-hop repeater systems suggest a more capacity-thriving repeater system version.

Actually, the gradual maximum overall capacity improvement that occurs from conventional distribution BPL topologies to ones with two-hop repeater systems and, finally, to those with three-hop repeater systems is highlighted in Figures 11(a)-11(d) where different indicative distribution BPL topologies and coupling schemes are examined.

From Figures 11(a)-11(d), it is evident that, through the deployment of three-hop repeater systems, apart from the mitigation of capacity discrepancies among different topologies of the same BPL network type, significant capacity differences may be assuaged among overhead and underground MV/BPL and LV/BPL networks.

Nevertheless, due to the bus-bar nature of distribution BPL networks, the aggravated topologies of these networks define the overall network capacity. Actually, the most aggravated topologies of BPL networks impose an upper overall network capacity limit (capacity ceiling) that is determined as the minimum of the maximum overall capacities of Figures 11(a)-11(d). Multihop repeater systems drastically improve this upper overall network capacity limit; in the case of conventional distribution BPL networks, distribution BPL network with two-hop repeater systems, and distribution BPL networks with three-hop repeater systems, this upper overall network capacity limit is equal to $378 \mathrm{Mbps}, 474 \mathrm{Mbps}$, and $580 \mathrm{Mbps}$, respectively, corresponding to approximate $100 \mathrm{Mbps}$ increase of overall network capacity limit per each installed repeater.

Except for the inherent upper overall network capacity limit, the design of high-bitrate distribution BPL topologies can impose strict common capacity thresholds across the overall network that consists of overhead and underground 


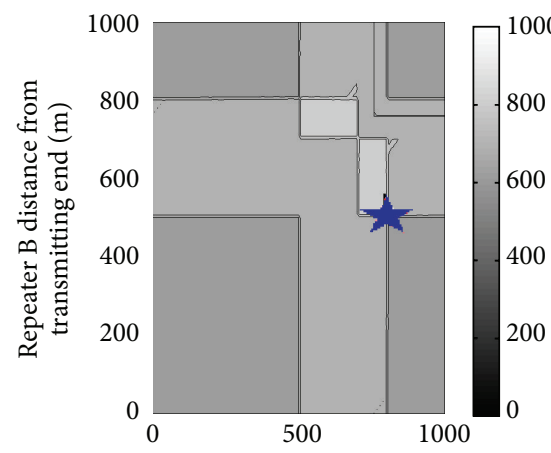

(a) Urban case $\mathrm{A} / \mathrm{WtG}^{1}$

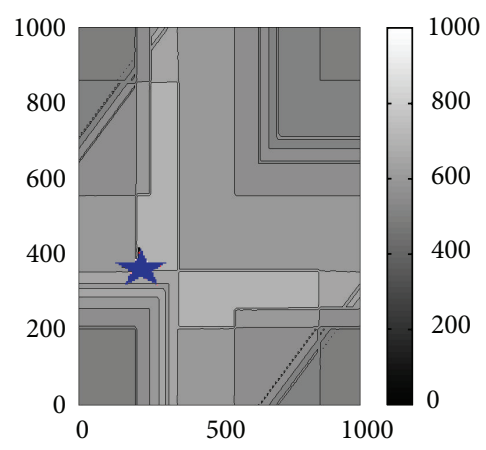

(b) Urban case $\mathrm{B} / \mathrm{WtG}^{1}$

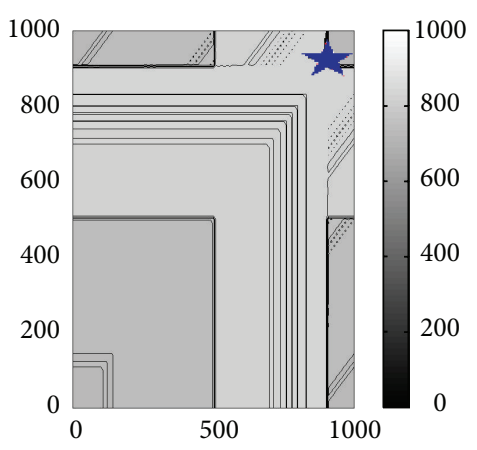

(c) Suburban case/ $\mathrm{WtG}^{1}$

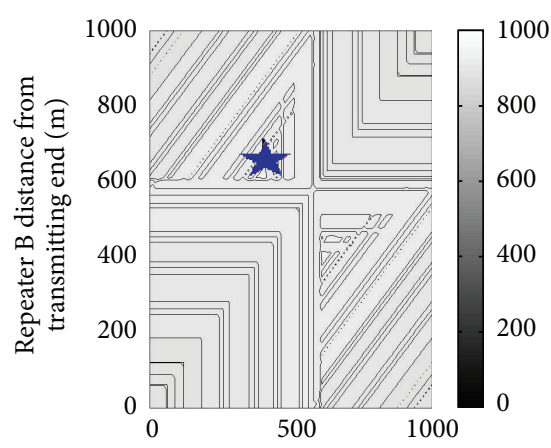

(d) Rural case $/ \mathrm{WtG}^{1}$

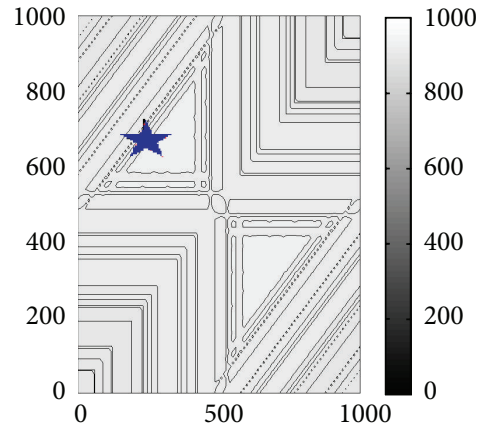

(e) "LOS" transmission case/WtG ${ }^{1}$

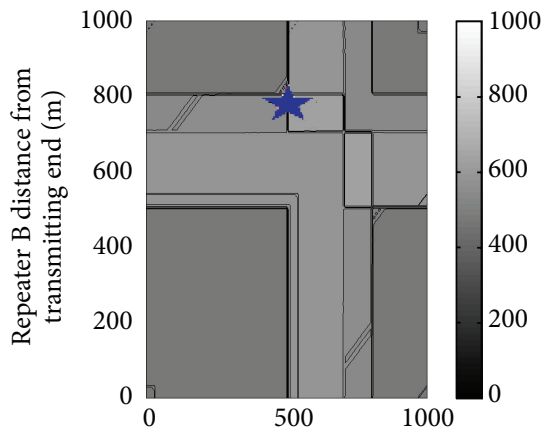

(f) Urban case $\mathrm{A} / \mathrm{WtW}^{1-2}$

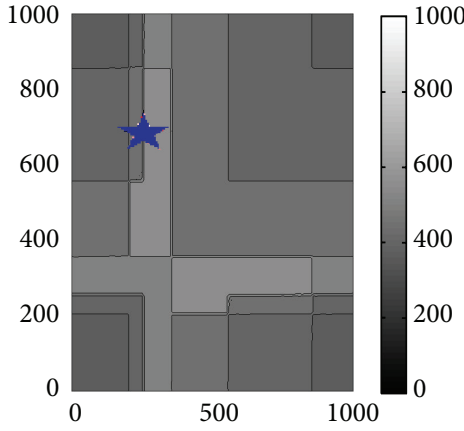

(g) Urban case $\mathrm{B} / \mathrm{WtW}^{1-2}$

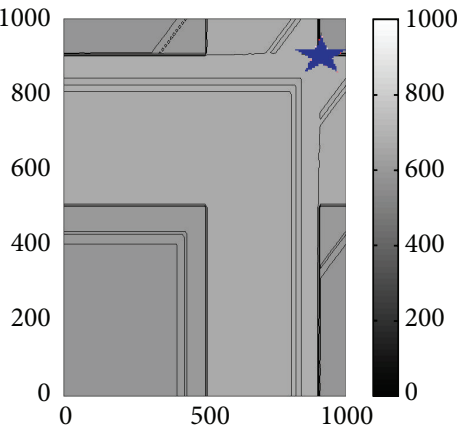

(h) Suburban case/WtW $\mathrm{Wt}^{1-2}$

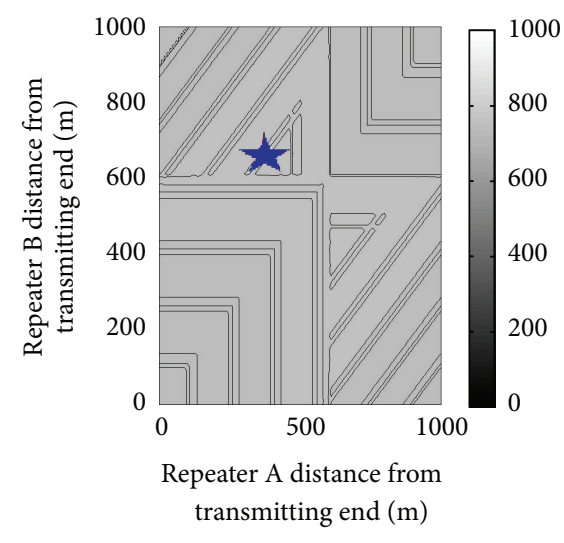

(i) Rural case $/ \mathrm{WtW}^{1-2}$

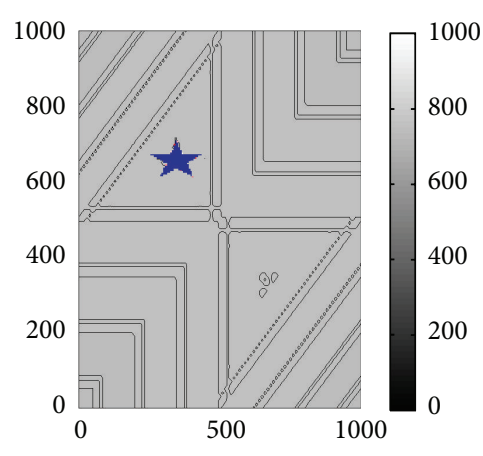

Repeater A distance from transmitting end $(\mathrm{m})$

(j) "LOS” transmission case/ $\mathrm{WtW}^{1-2}$

FIGURE 7: Overall capacity contour plots in Mbps of the five indicative overhead MV/BPL topologies versus repeaters distance from point A-see Figure 2-when three-hop repeater system is deployed for different coupling schemes (distance span is equal to $10 \mathrm{~m}$ ). Blue stars indicate maximum overall capacities. 


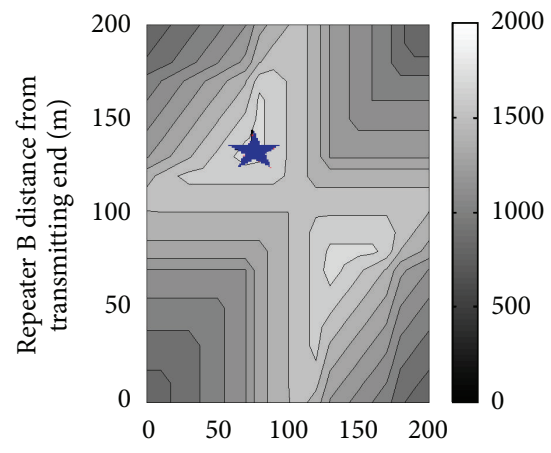

(a) Urban case $\mathrm{A} / \mathrm{StP}^{1}$

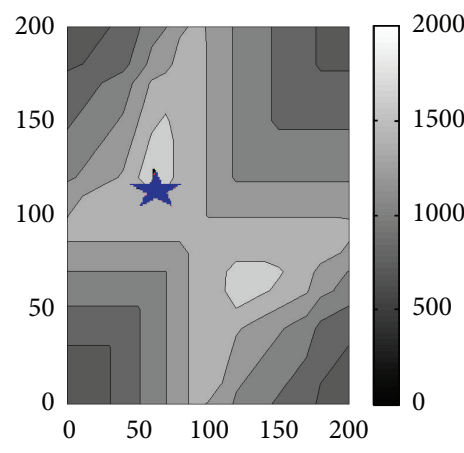

(b) Urban case $\mathrm{B} / \mathrm{StP}^{1}$

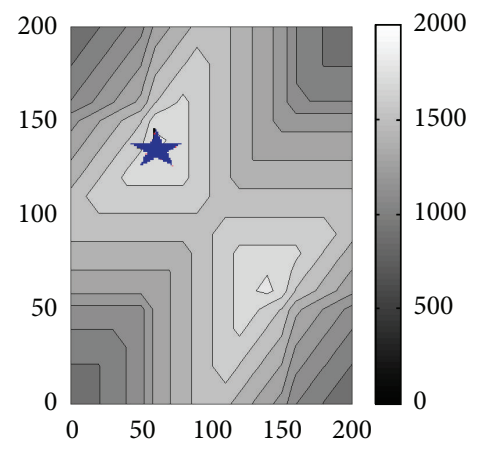

(c) Suburban case $/ \mathrm{StP}^{1}$

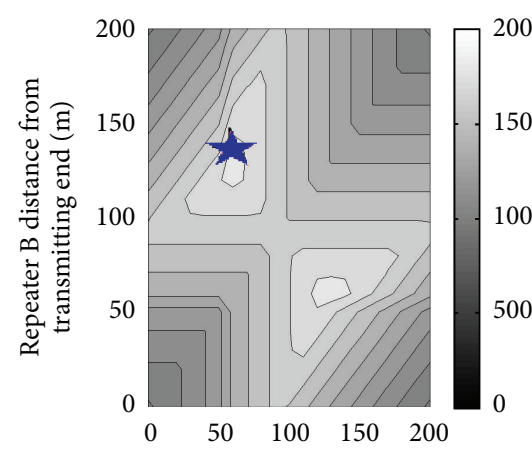

(d) Rural case $/ \mathrm{StP}^{1}$

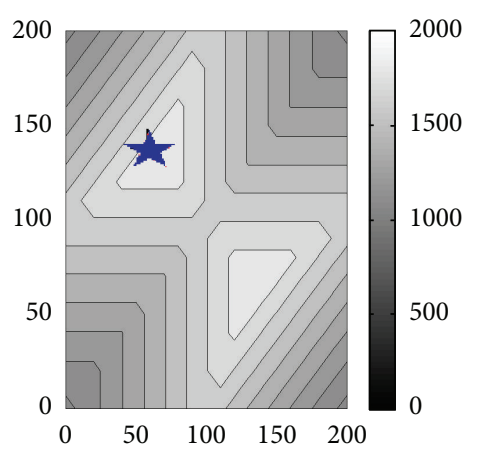

(e) "LOS" transmission case $/ \mathrm{StP}^{1}$

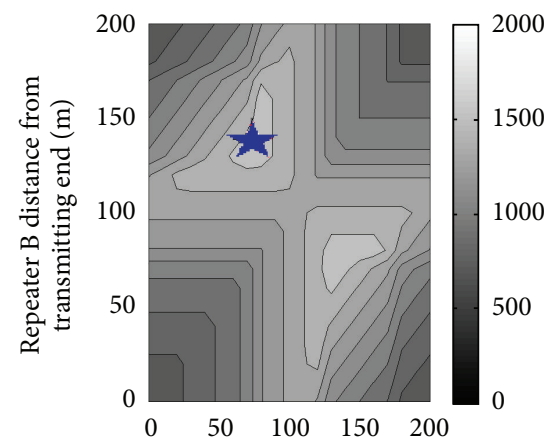

(f) Urban case $\mathrm{A} / \mathrm{PtP}^{1-2}$

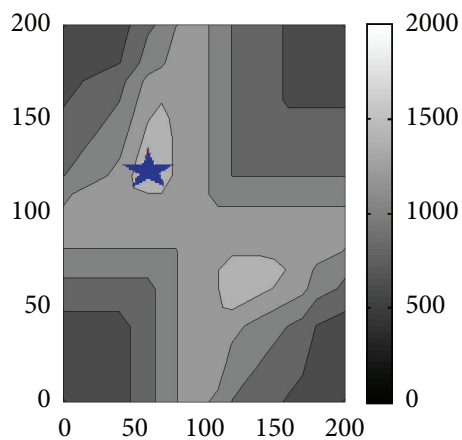

(g) Urban case $\mathrm{B} / \mathrm{PtP}^{1-2}$

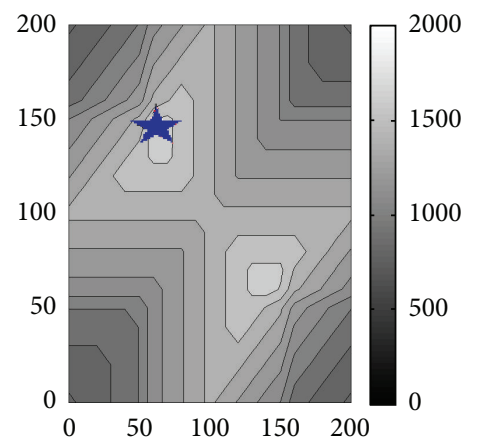

(h) Suburban case $/ \mathrm{PtP}^{1-2}$

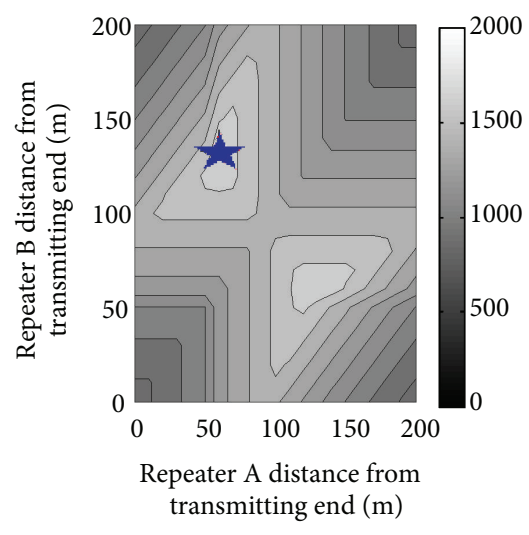

(i) Rural case $/ \mathrm{PtP}^{1-2}$

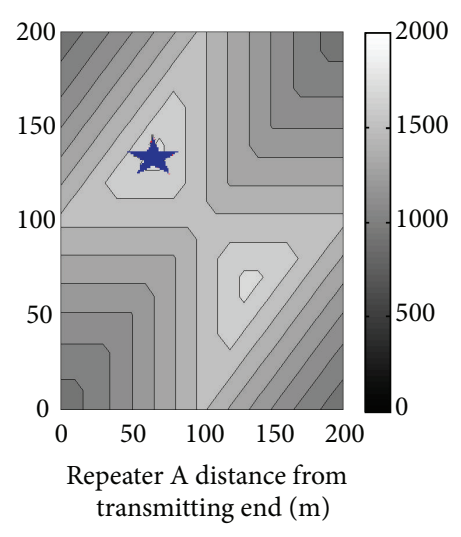

(j) "LOS" transmission case/ $\mathrm{PtP}^{1-2}$

FIGURE 8: Overall capacity contour plots in Mbps of the five indicative underground MV/BPL topologies versus repeaters distance from point A-see Figure 2-when three-hop repeater system is deployed for different coupling schemes (distance span is equal to $10 \mathrm{~m}$ ). Blue stars indicate maximum overall capacities. 


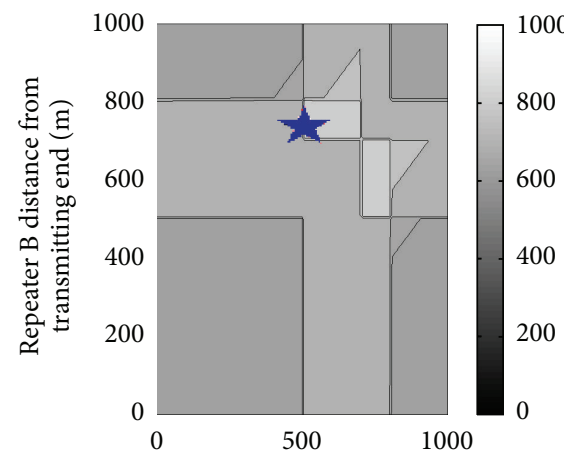

(a)

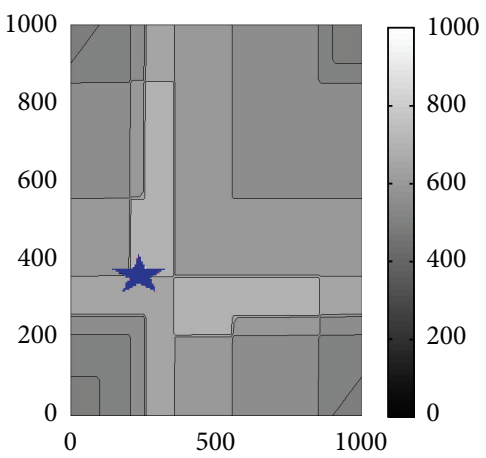

(b)

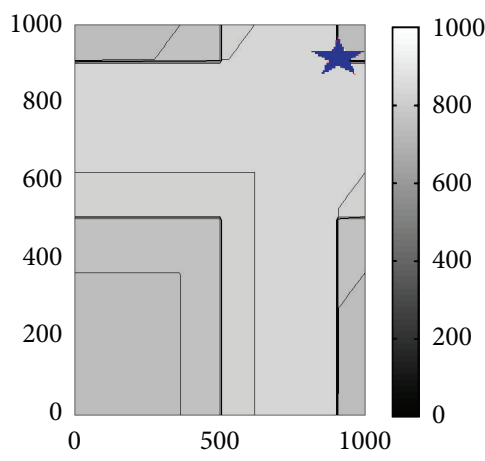

(c)

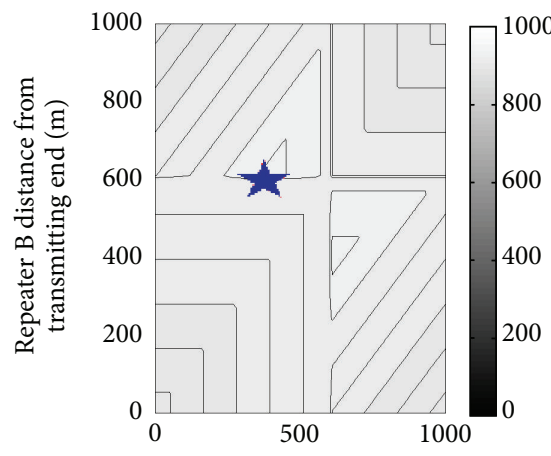

(d)

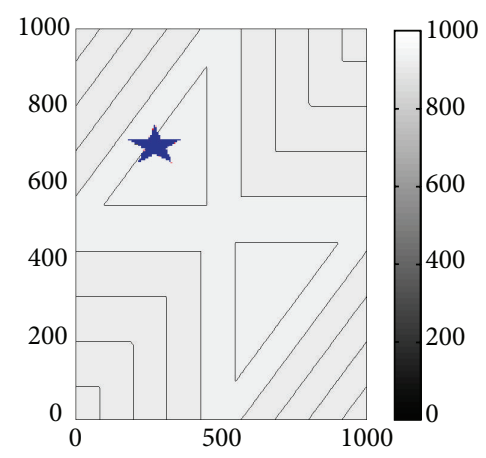

(e)

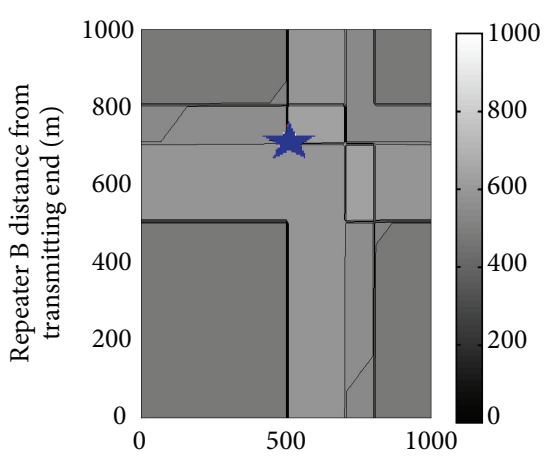

(f)

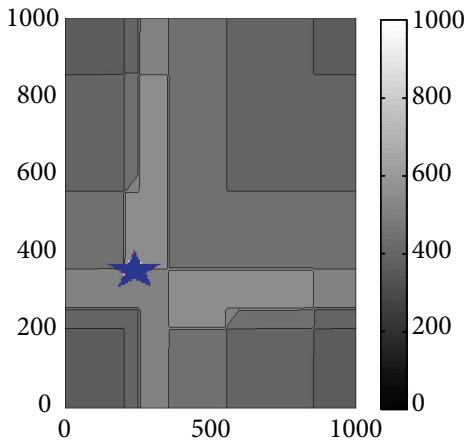

(g)

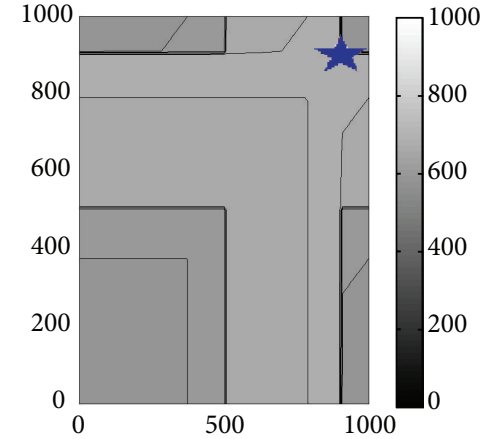

(h)

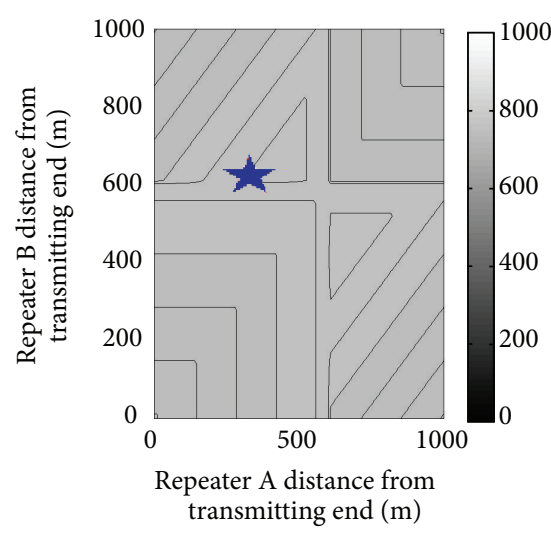

(i)

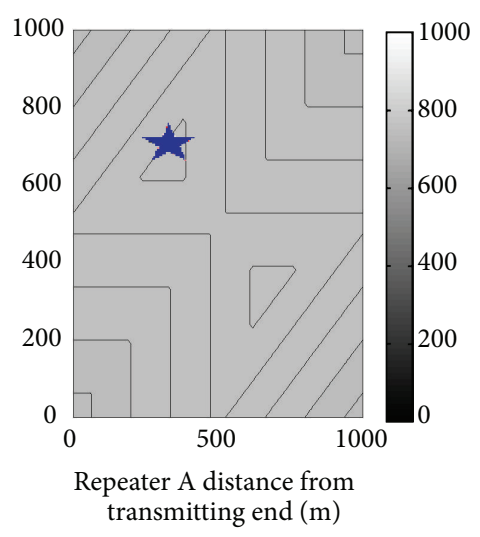

(j)

Figure 9: Same as in Figure 7 but for overhead LV/BPL topologies. 


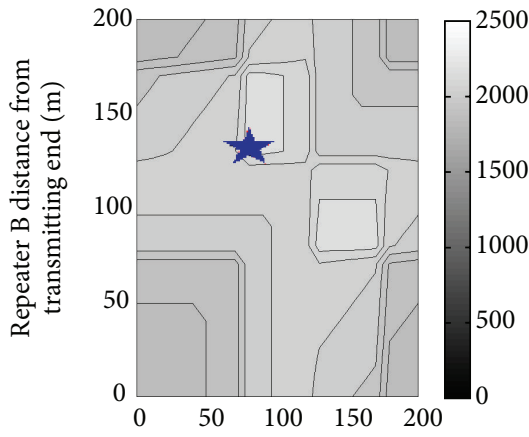

(a)

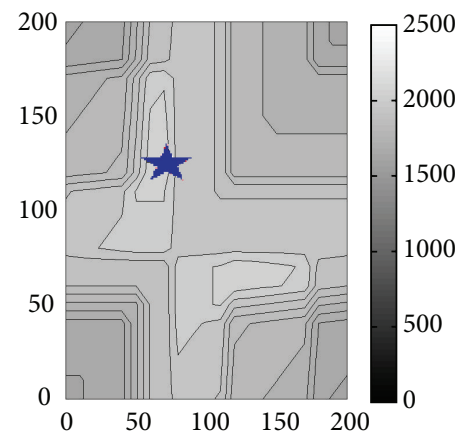

(b)

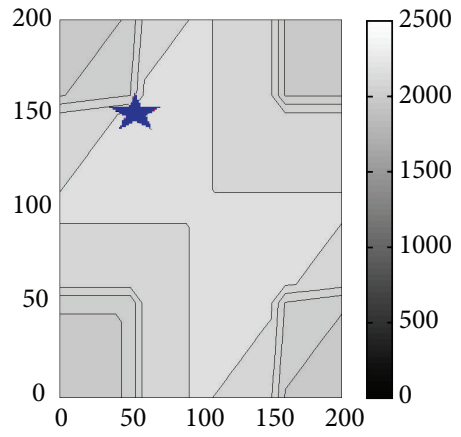

(c)

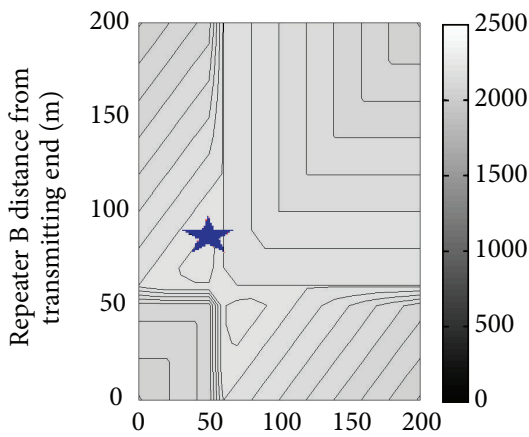

(d)

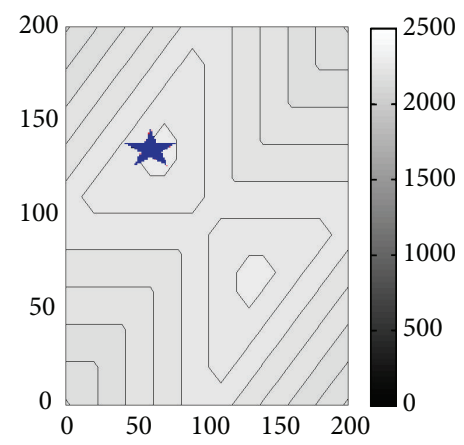

(e)

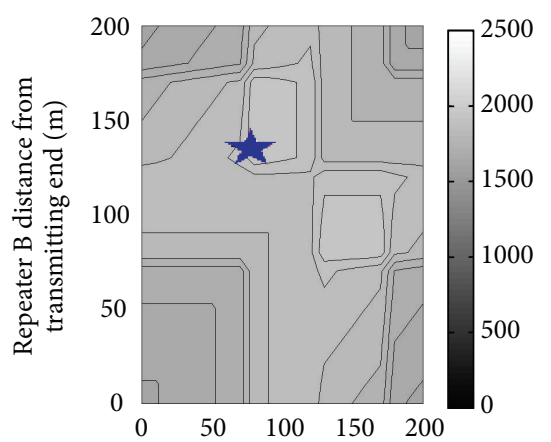

(f)

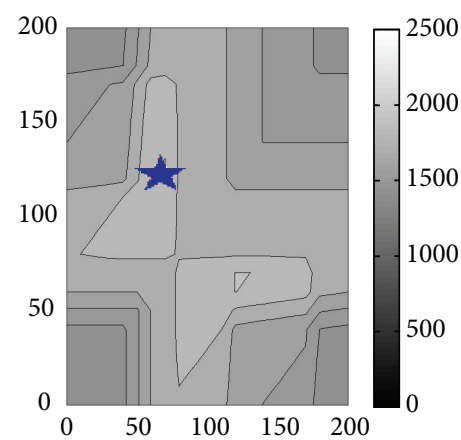

(g)

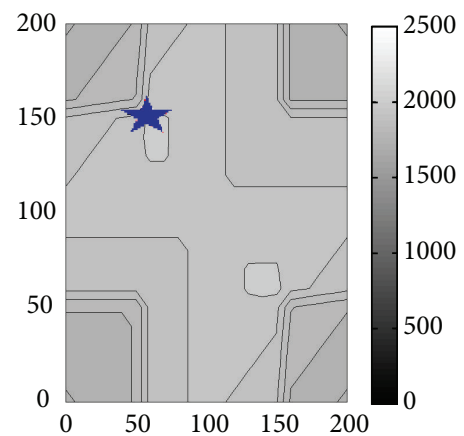

(h)

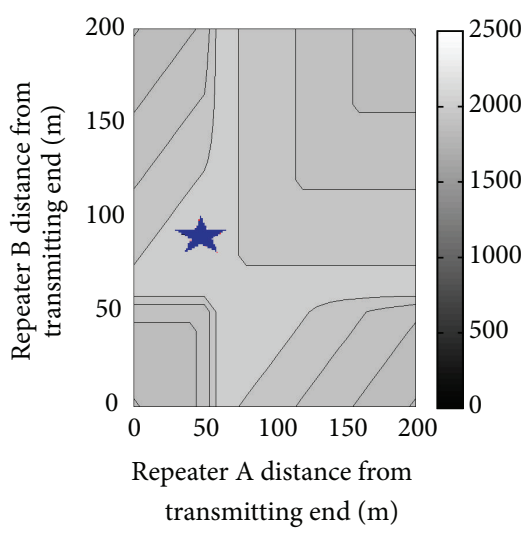

(i)

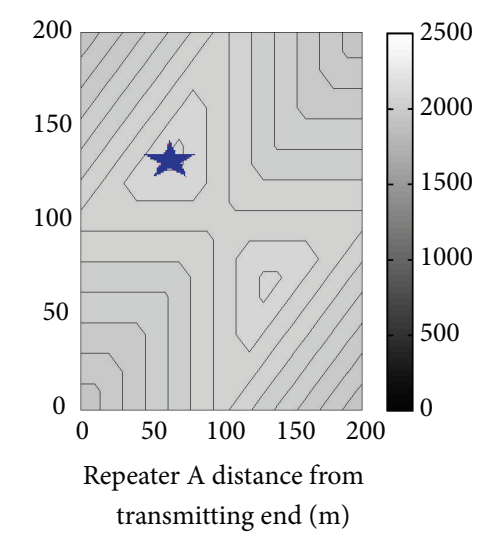

(j)

FIgURE 10: Same as in Figure 8 but for underground LV/BPL topologies. 


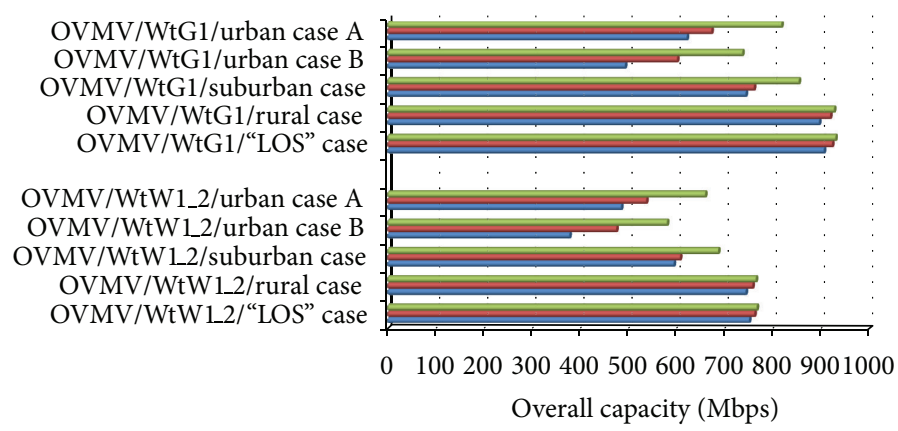

(a) Overhead MV/BPL topologies

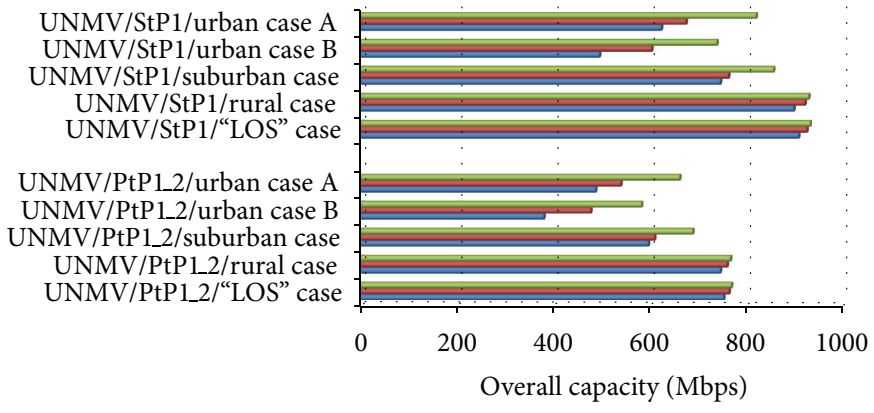

(b) Underground MV/BPL topologies

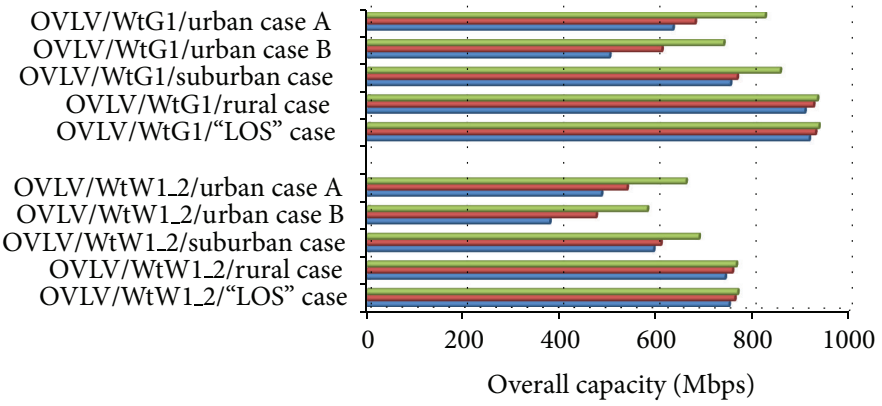

(c) Underground MV/BPL topologies

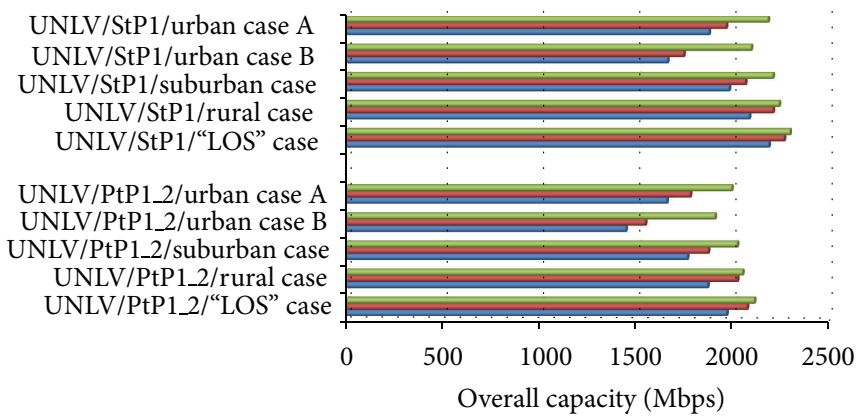

(d) Underground LV/BPL topologies

FIGURE 11: Maximum overall capacity of distribution BPL topologies with three-hop repeater systems (in green), distribution BPL topologies with two-hop repeater systems (in red), and conventional distribution BPL topologies (in blue) when different indicative BPL topologies and coupling scheme occur (OV: overhead, UN: underground, WtG1: WtG ${ }^{1}$ coupling scheme, WtW1_2: WtW ${ }^{1-2}$ coupling scheme, StP1: StP ${ }^{1}$ coupling scheme, and PtP1_2: $\mathrm{PtP}^{1-2}$ coupling scheme).

MV/BPL and LV/BPL topologies in order to satisfy EMC specifications that are locally and/or periodically imposed. Stricter EMC specifications impose lower IPSD limits that create additional capacity degradation in distribution BPL networks. Via the installation of three-hop repeater systems, there is a greater flexibility regarding the capabilities of cooperative overhead and underground MV/BPL and LV/BPL networks when different EMC requirements are adopted.

Consequently, the above simulations and numerical results reveal the need of further broadband exploitation 
of overhead and underground MV/BPL and LV/BPL networks with multihop repeater system under the aegis of a unified transmission/distribution SG power grid. On the basis of multihop repeater systems, the BPL intraoperability/interoperability venture may be further promoted via the concepts of scalable capacities, standardized topologies, and free coupling scheme swap.

\section{Conclusions}

The broadband role of overhead and underground MV/BPL and LV/BPL networks with two- and three-hop repeater systems has been reviewed and analyzed in this paper. Their main contribution is the convenient and quick technology upgrade of the conventional distribution BPL networks offering crucial help towards the design/operation of cooperative distribution BPL networks in the oncoming SG network.

\section{References}

[1] A. G. Lazaropoulos, "Review and progress towards the common broadband management of high-voltage transmission grids: model expansion and comparative modal analysis," ISRN Electronics, vol. 2012, Article ID 935286, 18 pages, 2012.

[2] G. T. Heydt, C. C. Liu, A. G. Phadke, and V. Vittal, "Solutions for the crisis in electric power supply," IEEE Computer Applications in Power, vol. 14, no. 3, pp. 22-30, 2001.

[3] A. G. Lazaropoulos, "Towards modal integration of overhead and underground low-voltage and medium-voltage power line communication channels in the smart grid landscape: model expansion, broadband signal transmission characteristics, and statistical performance metrics (Invited Paper)," ISRN Signal Processing, vol. 2012, Article ID 121628, 17 pages, 2012.

[4] R. Schneiderman, "Smart grid represents a potentially huge market for the electronics industry," IEEE Signal Processing Magazine, vol. 27, no. 5, pp. 8-15, 2010.

[5] S. Galli, A. Scaglione, and Z. Wang, "For the grid and through the grid: the role of power line communications in the smart grid," Proceedings of the IEEE, vol. 99, no. 6, pp. 998-1027, 2011.

[6] M. O. Hasna and M. S. Alouini, "Outage probability of multihop transmission over Nakagami fading channels," IEEE Communications Letters, vol. 7, no. 5, pp. 216-218, 2003.

[7] J. Boyer, D. D. Falconer, and H. Yanikomeroglu, "Multihop diversity in wireless relaying channels," IEEE Transactions on Communications, vol. 52, no. 10, pp. 1820-1830, 2004.

[8] J. Wagner and A. Wittneben, "On capacity scaling of multiantenna multi-hop networks: the significance of the relaying strategy in the "long network limit"' IEEE Transactions on Information Theory, vol. 58, no. 4, pp. 2127-2143, 2012.

[9] Y. H. Kim, S. Choi, S. C. Kim, and J. H. Lee, "Capacity of OFDM two-hop relaying systems for medium-voltage powerline access networks," IEEE Transactions on Power Electronics, vol. 27, no. 2, pp. 886-894, 2012.

[10] X. Cheng, R. Cao, and L. Yang, "On the system capacity of relayaided Powerline Communications," in Proceedings of the IEEE International Symposium on Power Line Communications and Its Applications (ISPLC '11), pp. 170-175, Udine, Italy, April 2011.

[11] L. Lampe, R. Schober, and S. Yiu, "Distributed space-time coding for multihop transmission in power line communication networks," IEEE Journal on Selected Areas in Communications, vol. 24, no. 7, pp. 1389-1400, 2006.
[12] V. B. Balakirsky and A. J. Han Vinck, "Potential performance of PLC systems composed of several communication links," in Proceedings of the 9th International Symposium on Power Line Communications and Its Applications (ISPLC '05), pp. 12-16, Vancouver, BC, Canada, April 2005.

[13] A. G. Lazaropoulos, "Deployment concepts for overhead high voltage broadband over power lines connections with two-hop repeater system: capacity countermeasures against aggravated topologies and high noise environments," Progress in Electromagnetics Research B, vol. 44, pp. 283-307, 2012.

[14] G. Bumiller, L. Lampe, and H. Hrasnica, "Power line communication networks for large-scale control and automation systems," IEEE Communications Magazine, vol. 48, no. 4, pp. 106-113, 2010.

[15] L. Lampe and A. J. Han Vinck, "Cooperative multihop power line communications," in Proceedings of the 16th IEEE International Symposium on Power Line Communications and Its Applications (ISPLC '16), pp. 1-6, Beijing, China, March 2012.

[16] A. G. Lazaropoulos, "Factors influencing broadband transmission characteristics of underground low-voltage distribution networks," IET Communications, vol. 6, no. 17, pp. 2886-2893, 2012.

[17] A. G. Lazaropoulos and P. G. Cottis, "Transmission characteristics of overhead medium-voltage power-line communication channels," IEEE Transactions on Power Delivery, vol. 24, no. 3, pp. 1164-1173, 2009.

[18] A. G. Lazaropoulos and P. G. Cottis, "Capacity of overhead medium voltage power line communication channels," IEEE Transactions on Power Delivery, vol. 25, no. 2, pp. 723-733, 2010.

[19] A. G. Lazaropoulos and P. G. Cottis, "Broadband transmission via underground medium-voltage power lines-part I: transmission characteristics," IEEE Transactions on Power Delivery, vol. 25, no. 4, pp. 2414-2424, 2010.

[20] A. G. Lazaropoulos and P. G. Cottis, "Broadband transmission via underground medium-voltage power lines-part II: capacity," IEEE Transactions on Power Delivery, vol. 25, no. 4, pp. 2425-2434, 2010.

[21] A. G. Lazaropoulos, “Towards broadband over power lines systems integration: transmission characteristics of underground low-voltage distribution power lines," Progress in Electromagnetics Research B, vol. 39, pp. 89-114, 2012.

[22] A. G. Lazaropoulos, "Broadband transmission characteristics of overhead high-voltage power line communication channels," Progress in Electromagnetics Research B, vol. 36, pp. 373-398, 2012.

[23] A. G. Lazaropoulos, "Broadband transmission and statistical performance properties of overhead high-voltage transmission networks," Journal of Computer Networks and Communications, vol. 2012, Article ID 875632, 16 pages, 2012.

[24] OPERA1, "D44: report presenting the architecture of plc system, the electricity network topologies, the operating modes and the equipment over which PLC access system will be installed," IST Integrated Project 507667, 2005.

[25] P. Amirshahi and M. Kavehrad, "High-frequency characteristics of overhead multiconductor power lines for broadband communications," IEEE Journal on Selected Areas in Communications, vol. 24, no. 7, pp. 1292-1302, 2006.

[26] P. Amirshahi, Broadband access and home networking through powerline networks [Ph.D. thesis], The Pennsylvania-State University, University Park, Pa, USA, 2006. 
[27] M. D’Amore and M. S. Sarto, “A new formulation of lossy ground return parameters for transient analysis of multiconductor dissipative lines," IEEE Transactions on Power Delivery, vol. 12, no. 1, pp. 303-309, 1997.

[28] OPERA1, "D5: pathloss as a function of frequency, distance and network topology for various LV and MV European powerline networks," IST Integrated Project 507667, 2005.

[29] T. Calliacoudas and F. Issa, "Multiconductor transmission lines and cables solver, an efficient simulation tool for PL channel networks development," in Proceedings of the IEEE International Conference on Power Line Communications and Its Applications (ISPLC '02), Athens, Greece, March 2002.

[30] F. Issa, D. Chaffanjon, E. P. de la Bâthie, and A. Pacaud, "An efficient tool for modal analysis transmission lines for PLC networks development," in Proceedings of the IEEE International Conferences on Power Line Communications and Its Applications, Athens, Greece, March 2002.

[31] J. Anatory and N. Theethayi, "On the efficacy of using ground return in the broadband power-line communicationsa transmission-line analysis," IEEE Transactions on Power Delivery, vol. 23, no. 1, pp. 132-139, 2008.

[32] P. C. J. M. van der Wielen, On-line detection and location of partial discharges in medium-voltage power cables [Ph.D. thesis], Eindhoven University of Technology, Eindhoven, The Netherlands, 2005.

[33] P. C. J. M. van der Wielen, E. F. Steennis, and P. A. A. F. Wouters, "Fundamental aspects of excitation and propagation of online partial discharge signals in three-phase medium voltage cable systems," IEEE Transactions on Dielectrics and Electrical Insulation, vol. 10, no. 4, pp. 678-688, 2003.

[34] T. Sartenaer, Multiuser communications over frequency selective wired channels and applications to the powerline access network [Ph.D. thesis], Université Catholique de Louvain, Louvain-laNeuve, Belgium, 2004.

[35] T. Sartenaer and P. Delogne, "Powerline cables modelling for broadband communications," in Proceedings of the IEEE International Conference on Power Line Communications and its Applications (ISPLC '01), pp. 331-337, Malmö, Sweden, April 2001.

[36] M. Tang and M. Zhai, "Research of transmission parameters of four-conductor cables for power line communication," in Proceedings of the International Conference on Computer Science and Software Engineering, vol. 5, pp. 1306-1309, Wuhan, China, December 2008.

[37] N. Theethayi, Electromagnetic interference in distributed outdoor electrical systems, with an emphasis on lightning interaction with electrified railway network [Ph.D. thesis], Uppsala University, Uppsala, Sweden, 2005.

[38] S. Galli, A. Scaglione, and K. Dostert, "Broadband is power: internet access through the power line network," IEEE Communications Magazine, vol. 41, no. 5, pp. 82-83, 2003.

[39] T. Banwell and S. Galli, "A novel approach to the modeling of the indoor power line channel part I: circuit analysis and companion model," IEEE Transactions on Power Delivery, vol. 20, no. 2 I, pp. 655-663, 2005.

[40] T. Sartenaer and P. Delogne, "Deterministic modeling of the (shielded) outdoor power line channel based on the Multiconductor Transmission Line equations," IEEE Journal on Selected Areas in Communications, vol. 24, no. 7, pp. 1277-1290, 2006.

[41] J. Anatory, N. Theethayi, R. Thottappillil, M. M. Kissaka, and N. H. Mvungi, "The influence of load impedance, line length, and branches on underground cable power-line communications (PLC) systems," IEEE Transactions on Power Delivery, vol. 23, no. 1, pp. 180-187, 2008.

[42] J. Anatory, N. Theethayi, and R. Thottappillil, "Power-line communication channel model for interconnected networkspart II: multiconductor system," IEEE Transactions on Power Delivery, vol. 24, no. 1, pp. 124-128, 2009.

[43] J. Anatory, N. Theethayi, R. Thottappillil, M. Kissaka, and N. Mvungi, "The effects of load impedance, line length, and branches in typical low-voltage channels of the BPLC systems of developing countries: transmission-line analyses," IEEE Transactions on Power Delivery, vol. 24, no. 2, pp. 621-629, 2009.

[44] S. Galli and T. Banwell, "A novel approach to the modeling of the indoor power line channel-part II: transfer function and its properties," IEEE Transactions on Power Delivery, vol. 20, no. 3, pp. 1869-1878, 2005.

[45] H. Meng, S. Chen, Y. L. Guan et al., "Modeling of transfer characteristics for the broadband power line communication channel," IEEE Transactions on Power Delivery, vol. 19, no. 3, pp. 1057-1064, 2004.

[46] S. Galli and T. C. Banwell, "A deterministic frequency-domain model for the indoor power line transfer function," IEEE Journal on Selected Areas in Communications, vol. 24, no. 7, pp. 13041315, 2006.

[47] A. Cataliotti, A. Daidone, and G. Tinè, "Power line communication in medium voltage systems: characterization of MV cables," IEEE Transactions on Power Delivery, vol. 23, no. 4, pp. 18961902, 2008.

[48] A. M. Tonello, F. Versolatto, B. Béjar, and S. Zazo, "A fitting algorithm for random modeling the PLC channel," IEEE Transactions on Power Delivery, vol. 27, no. 3, pp. 1477-1484, 2012.

[49] J. Anatory, N. Theethayi, R. Thottappillil, M. M. Kissaka, and N. H. Mvungi, "The effects of load impedance, line length, and branches in the BPLC-transmission-line analysis for indoor voltage channel," IEEE Transactions on Power Delivery, vol. 22, no. 4, pp. 2150-2155, 2007.

[50] M. Kuhn, S. Berger, I. Hammerström, and A. Wittneben, "Power line enhanced cooperative wireless communications," IEEE Journal on Selected Areas in Communications, vol. 24, no. 7, pp. 1401-1410, 2006.

[51] S. Liu and L. J. Greenstein, "Emission characteristics and interference constraint of overhead medium-voltage Broadband Power Line (BPL) systems," in Proceedings of the IEEE Global Telecommunications Conference (GLOBECOM '08), pp. 29212925, New Orleans, La, USA, December 2008.

[52] R. Aquilué, Power line communications for the electrical utility: physical layer design and channel modeling [Ph.D. thesis], Universitat Ramon Llull, Enginyeria I Arquitectura La Salle, Barcelona, Spain, 2008.

[53] J. Song, C. Pan, Q. Wu et al., "Field trial of digital video transmission over medium-voltage powerline with time-domain synchronous orthogonal frequency division multiplexing technology," in Proceedings of the International Symposium on Power Line Communications and Its Applications (ISPLC '07), pp. 559564, Pisa, Italy, March 2007.

[54] M. Zimmermann and K. Dostert, "Analysis and modeling of impulsive noise in broad-band powerline communications," IEEE Transactions on Electromagnetic Compatibility, vol. 44, no. 1, pp. 249-258, 2002.

[55] M. Katayama, T. Yamazato, and H. Okada, "A mathematical model of noise in narrowband power line communication 
systems," IEEE Journal on Selected Areas in Communications, vol. 24 , no. 7, pp. 1267-1276, 2006.

[56] Ofcom, "DS2 PLT Measurements in Crieff Ofcom Technical Report 793, Part 2, May 2005, ”.

[57] M. Gebhardt, F. Weinmann, and K. Dostert, "Physical and regulatory constraints for communication over the power supply grid," IEEE Communications Magazine, vol. 41, no. 5, pp. 84-90, 2003.

[58] Ofcom, "Amperion PLT Measurements in Crieff," Ofcom Technical Report, September 2005, http://www.ofcom.org.uk/ research/technology/research/archive/cet/powerline/.

[59] NATO, "HF Interference, Procedures and Tools (Interférences HF, procédures et outils) Final Report of NATO RTO Information Systems Technology," RTO Technical Report TR-IST-050, North Atlantic Treaty Organisation, 2007. 

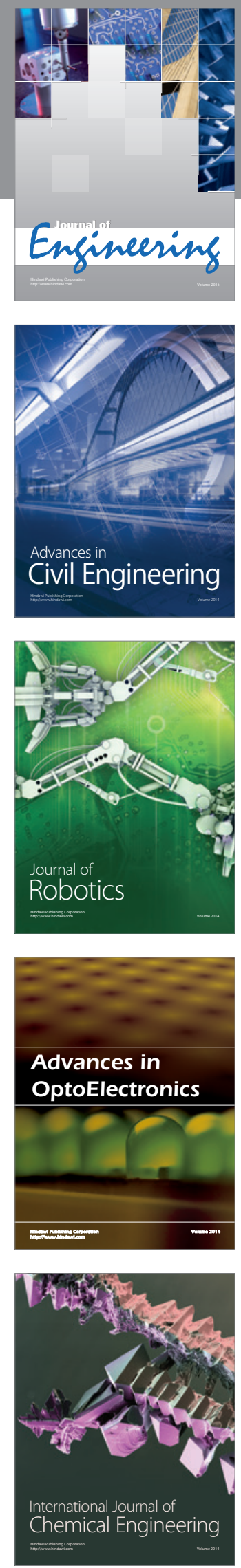

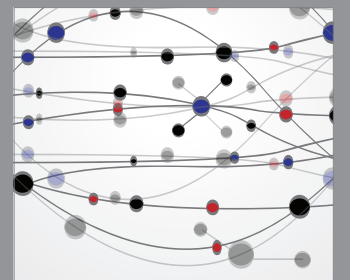

The Scientific World Journal
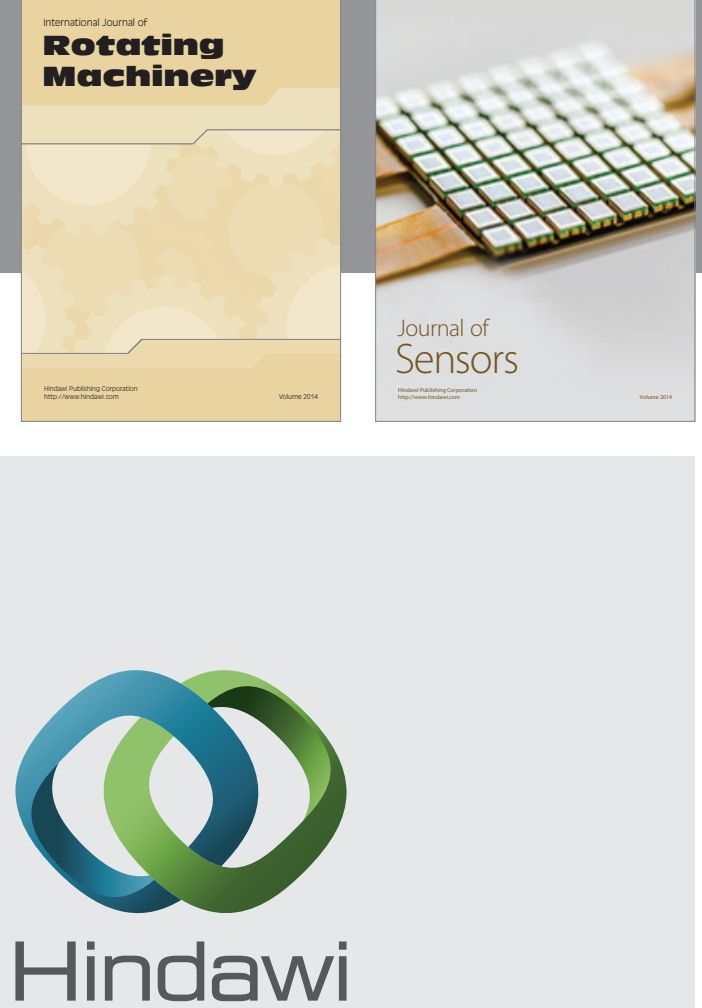

Submit your manuscripts at http://www.hindawi.com
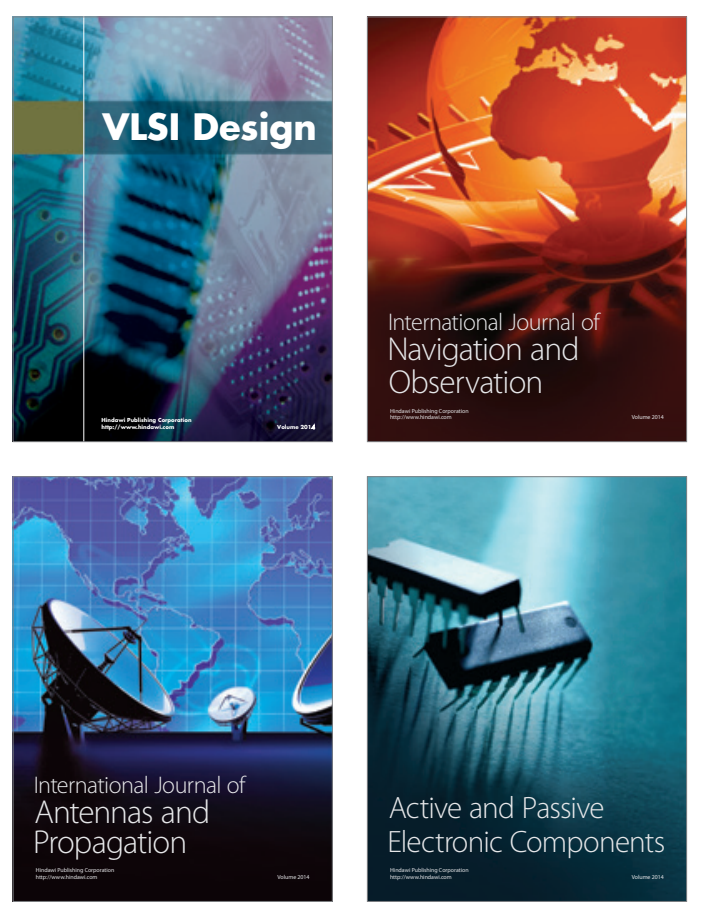
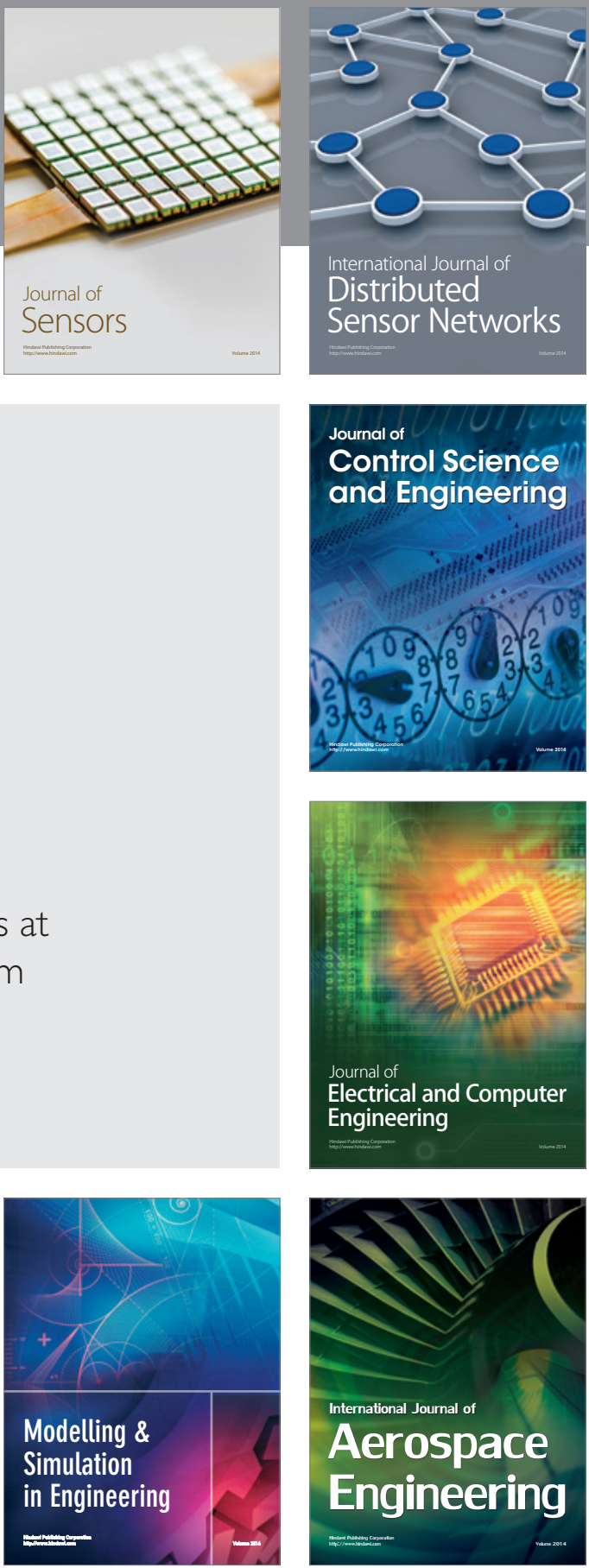

Journal of

Control Science

and Engineering
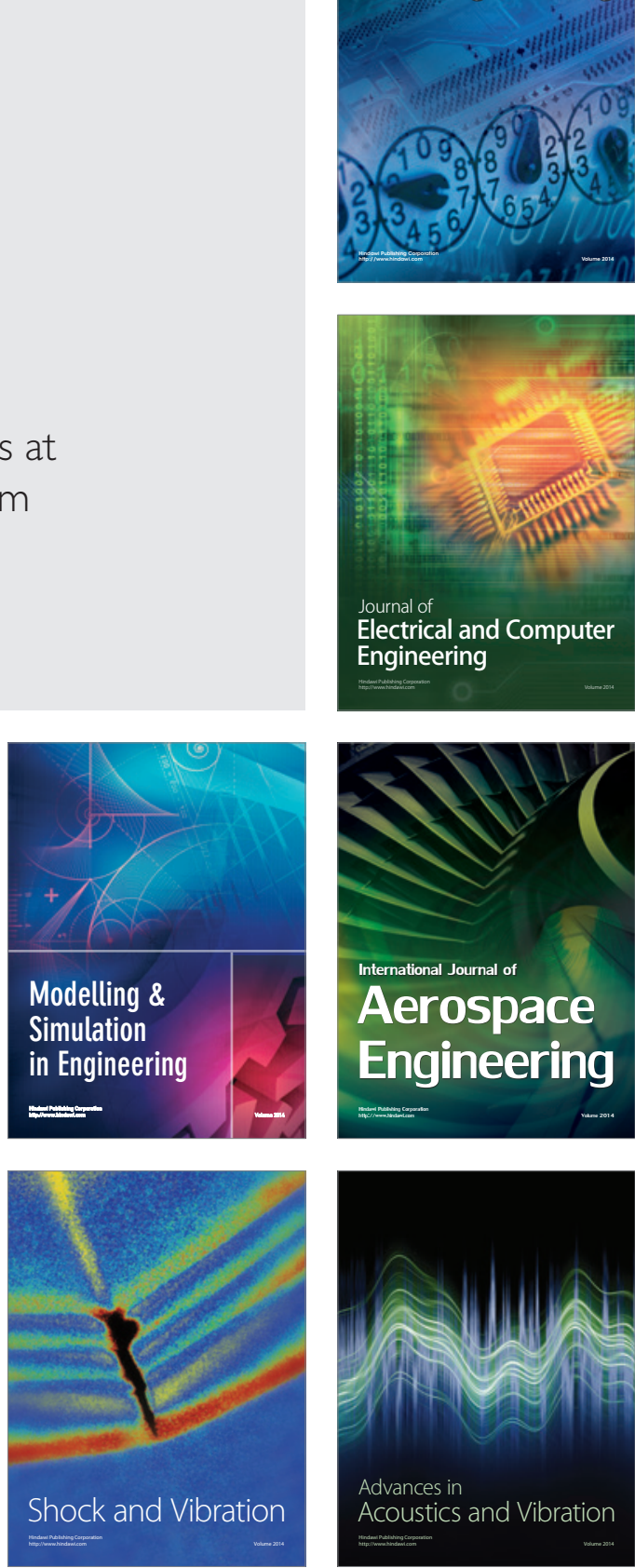